CUADERNOS DE ESTUDIOS GALLEGOS, LXIII Núm. 129 (enero-diciembre 2016), págs. 163-203

ISSN: $0210-847 \mathrm{X}$

DOI: 10.3989/ceg.2016.129.05

\title{
HALLAZGOS INÉDITOS DE MONEDA MEDIEVAL EN GALICIA
}

\author{
Pablo NúÑEZ Meneses \\ Universidad de Santiago de Compostela
}

Copyright: (c) 2016 CSIC. Este es un artículo de acceso abierto distribuido bajo los términos de una licencia de uso y distribución Creative Commons Attribution (CC-by) España 3.0.

Cómo citar/Citation: Pablo NúÑEz Meneses, "Hallazgos inéditos de moneda medieval en Galicia”, Cuadernos de Estudios Gallegos, 63, núm. 129 (2016), págs. 163-203, DOI: http://dx.doi. org/10.3989/ceg.2016.129.05 


\section{HALLAGOS INÉDITOS DE MONEDA MEDIEVAL EN GALICIA}

RESUMEN

El presente trabajo pretende dar a conocer el material numismático medieval hallado en Galicia que aún permanecía inédito fuera de las instituciones donde se preserva, conscientes de la importancia del conocimiento de todos los datos posibles para la interpretación histórica, siendo los hallazgos de moneda el más fiel testimonio, junto a la documentación, del uso y circulación de la moneda en todas épocas. Hemos accedido a los fondos numismáticos de diversos museos e instituciones de Galicia que amablemente nos abrieron sus puertas, descubriendo, en ocasiones, monedas medievales que habían pasado desapercibidas u otras mal catalogadas. En ocasiones, sin embargo, la catalogación era perfecta y el trabajo metrológico y fotográfico estaba ya realizado.

Esta búsqueda era necesaria dado los escasos hallazgos publicados de moneda medieval para con el Noroeste, insuficientes como para establecer conclusiones sólidas. Nos ha permitido concluir, entre otras cuestiones, que la moneda ya está muy presente en el rural gallego en la Plena Edad Media o que la moneda portuguesa tuvo inmensa presencia en la Galicia bajomedieval. Aún así sabemos que la reciente actividad arqueológica en Galicia está descubriendo nuevos ejemplares que aumentarán el caudal de conocimientos actuales, permitiendo conocer si ha habido o no pervivencia de numerario en varias décadas o si el desuso de la moneda tras la caída del Imperio Romano ha sido tan intensa como asemeja hasta la recuperación plenomedieval. Palabras Clave: moneda, época medieval, Galicia.

\section{ACHÁDEGOS INÉDITOS DE MOEDA MEDIEVAL EN GALICIA}

RESUMO

O presente traballo pretende dar a coñecer aquel material numismático medieval achado en Galicia e que aínda permanecía inédito fóra das institucións onde se preserva, sabedores da importancia do coñecemento de tódolos datos posibles para a ulterior interpretación histórica, sendo os achádegos de moeda a máis fiel testemuña, xunto coa documentación, do uso e circulación da moeda en todas épocas. Accedemos aos fondos numismáticos de diversos museos e institucións de Galicia que amablemente nos abriron as súas portas, atopando, en ocasións, moedas medievais que pasaran desapercibidas ou outras mal catalogadas. En ocasións, con todo, a catalogación era perfecta e o traballo metrolóxico e fotográfico estaba xa realizado.

Esta procura era necesaria dado os escasos achádegos publicados de moeda medieval para co Noroeste, insuficientes como para establecermos conclusións sólidas. Permitiunos concluír, entre outras cuestións, que a moeda xa está moi presente no rural galego na Plena Idade Media, ou que a moeda portuguesa tivo inmensa presenza na Galicia baixomedieval. Aínda así sabemos que a recente actividade arqueolóxica en Galicia está descubrindo novos exemplares que aumentarán o caudal de coñecementos actuais, permitindo coñecer se houbo ou non pervivencia do numerario en varias décadas ou se o desplome no uso da moeda trala caída do Imperio Romano foi tan intenso como asemella ata a recuperación plenomedieval.

PALABRAS Clave: moeda, época medieval, Galicia.

\section{UNPUBLISHED FINDINGS OF MEDIEVAL COIN IN GALICIA}

\section{ABSTRACT}

This work wants to promote medieval mumismatic material found in Galicia, which still remained unpublished outside the institutions where it is preserved, aware of the importance of the knowledge of all possible data for historical interpretation, being the coin finds the truer testimony, along with the documentation, of the use and circulation of money at all times. We have visited numismatists funds from principal Galician museums and institutions who kindly opened us their doors, discovering, on occasions, medieval coins that had gone unnoticed or other badly catalogued. Sometimes, however, the cataloguing was perfect and the metrological work and photography was already done.

This search was necessary because of the scarce published medieval coin finds for Northwest Spain, insufficient to draw firm conclusions. It has allowed us to conclude, among other things, that coins and money are already very present in rural areas in XII and XIII Galician middle ages, or that Portuguese coins had immense presence in medieval XIV and XV Galicia. Nevertheless, we know that recent archaeological activity in Galicia is discovering new specimens that will increase our knowledge, allowing us to know if there has been or not coin survival in several decades or if depression of the use of money after the fall of the Roman Empire has been so intense as it seems up to the recovery of XII century.

KeY WORDs: coin, Middle Ages, Galicia. 
Recibido/Received: 01/04/2016

Aceptado/Accepted: 14/06/2016

$\mathrm{E}$ $\mathrm{n}$ toda investigación histórica, y la historia monetaria no es una excepción, los materiales sobre los que se asienta el discurso historiográfico son tan importantes como que son los que encauzan la interpretación hacia una $\mathrm{u}$ otra dirección. En la numismática es la moneda el objeto de estudio, en sentido mucho más amplio que el que lo ha relegado al mero objeto de colección, siendo, en efecto, testimonio histórico de situaciones políticas, económicas, sociales o culturales en su más amplia significación. Ya decía Pierre David que tan sólo los trientes visigodos, sin más, autentican la originalidad del Parroquiale suevorum $^{1}$, o Marques que la moneda sueva es quizás el material más representativo y genuinamente propio del oscuro reino suevo ${ }^{2}$. La vuelta a la moneda de busto en el vellón de Sancho IV se pone en relación con la búsqueda de legitimidad por parte del monarca una vez fallecido su padre Alfonso X, con el que había estado en guerra ${ }^{3}$, y las siglas monetarias SIDNS en los reales, cornados y dineros de Enrique II sólo pueden corresponder a la ceca compostelana que se había re-abierto tras que la invasión portuguesa hubiera tomado en sus manos la ceca más productiva y longeva de la historia de Galicia ${ }^{4}$, el taller coruñés. Moneda y peregrinación a Compostela ${ }^{5}$, moneda y mundo rural medieval ${ }^{6}$, son tan sólo

\footnotetext{
1 Pierre DAVID, Études historiques sur la Galice et le Portugal du VI au XII siècle, Coimbra, Instituto de Estudios Históricos, 1947, pág. 35.

2 Mário Gomes Marques, A moeda peninsular na idade das trevas, Sintra, Instituto de Sintra, 1998, pág. 15 y ss.

3 Manuel Aulló Costilla, "Cornados de Sancho IV”, Nvmisma, 16 (1955), págs. 65-85.

4 Raquel Casal García, Goretti González Vila, Antonio Roma Valdés, "Monedas de Enrique II fabricadas entre 1369 y 1373: una posible emisión compostelana", Gaceta numismática, 174-175 (2009), págs. 21-34.

5 José SuÁrez Otero, "Moneda, peregrinación y comercio. Una nueva perspectiva del Camino de Santiago en la Edad Media", en Serafín Moralejo y Fernando López Alsina, VIII Memorial Filgueira Valverde. Reflejos da peregrinación e do culto a Santiago, Pontevedra, Universidad de Vigo, 2009, págs. 81-114.

6 Pablo NúÑez Meneses, "Moneda y mundo rural en la documentación samonense medieval”, en Actas del Lugo Numismático 2016, a publicar en ANVAR.es (julio 2016).
} 
algunos de los incontables ejemplos que asocian la importancia de la moneda con el devenir histórico en su totalidad.

Es el uso y función de la moneda una de las cuestiones clave a explicar por la Historia monetaria de todas épocas, y no puede realizarse sin el conocimiento numismático de los ejemplares existentes, su presencia en hallazgos y arqueología, la documentación que se refiere a ellos directa o indirectamente y su contextualización histórica y monetaria, realizando las correspondientes analogías con otras geografías y cronologías. Desde estas perspectivas no sería incongruente el tratar el uso y función de la moneda en los llamados siglos sin moneda (siglos VIII al $\mathrm{XI}$ en el NO peninsular ${ }^{7}$ ), ya que aunque la moneda propia sigue siendo inexistente, no lo es la foránea y mucho menos la documentación que habla de moneda de cuenta. Además esta situación de pingue uso físico de la moneda en estos siglos está imbricada en un proceso global que une moneda germana ${ }^{8}$ y moneda plenomedieval, que une al fin y al cabo dos Edades monetarias, la Antigua y la Media, con momentos antagónicos en la percepción de economía y moneda, no sólo por sus formas y contenido metálico, sino por la función que desempeñaron, como la moneda germana más bien inserta en la economía del don, o la moneda plenomedieval más bien inserta en la economía del comercio.

Es la Historia monetaria medieval una época difícil de estudiar, no sólo por los más de mil años que engloba y los tan diversos procesos, sino por lo escaso e impreciso de muchas fuentes, especialmente altomedievales. Aún así han surgido nuevos trabajos esclarecedores que han dado luz a las principales incógnitas dentro de la Historia monetaria del Noroeste peninsular, como los de Marques, Cabral \& Metcalf ${ }^{10}$, Pliego ${ }^{11}$, Núñez $^{12}$, Suárez ${ }^{13}$ o Roma ${ }^{14}$, entre otros. Éste último autor ha sintetizado, tras su Tesis doctoral, gran parte de los hallazgos de moneda

\footnotetext{
7 Pablo NúÑEz Meneses, “¿Economía natural o monetaria en la Galicia de los siglos VIII al XI?”, OMNI, 6 (2013), págs. 146-155.

8 Para muchos el epílogo de la moneda romana, aunque tan sólo formalmente. La función de la moneda es totalmente distinta, concibiéndose en este último caso como moneda de prestigio, inserta en la circulación de bienes de tipo simbólico (dones).

9 M. Gomes Marques, A moeda peninsular..

${ }^{10}$ Joào Manuel Peixoto Cabral y David Michael Metcalf, A moeda sueva. Suevic Coinage, Porto, Sociedade Portuguesa Numismática, 1997.

${ }^{11}$ Ruth Pliego VÁzquez, La moneda visigoda, Vols. I y II, Sevilla, Universidad de Sevilla, 2009.

${ }^{12}$ Pablo NúÑEz Meneses, "Subida de la vida en el reino astur-leonés tras el cambio monetario del sueldo de oro al sueldo de plata: ¿mito o realidad?", Medievalismo, 25 (2015), págs. 357-368.

${ }^{13}$ José Sú́rez Otero, "Conjunto de monedas medievales aparecidas en las excavaciones de la Catedral de Santiago", en Serafín Moralejo y Fernando López Alsina (eds.), Santiago, camino de Europa. Culto y cultura en la peregrinación a Compostela, Madrid, Caja de Madrid, 1993, págs. 279-283.

${ }^{14}$ Antonio Roma VaLdés, Moneda y sistemas monetarios en Castilla y en León durante la Edad Media (1087-1366), Barcelona, ANE; Madrid, MCM, 2000.
} 
castellano-leonesa medieval, además de realizar estupendas interpretaciones en esta y otras obras ${ }^{15}$.

Queremos ampliar ahora este compendio, conscientes de la vital importancia que significa el conocimiento de cuantos más datos en toda investigación histórica, recordando que la intensificación, desde hace algunos lustros, de la actividad arqueológica en Galicia, acrecenta a pasos de gigante la cantidad de materiales hallados, también monetarios.

Hemos querido centrarnos en los fondos numismáticos de los museos provinciales y arqueológicos de Galicia, a donde van a parar gran parte de los materiales hallados ${ }^{16}$, además de algún servicio arqueológico como el del Concello de Lugo, con amplios fondos, sobre todo y lógicamente, de moneda romana. Sea moneda con o sin registro arqueológico, lo que necesitamos es que su procedencia haya sido registrada, debiéndose, en muchos casos, a encuentros fortuitos que han sido por suerte puestos en conociento de las pertinentes autoridades, no siempre depositando en institución pública los materiales encontrados.

Somos conscientes de que el origen exacto de muchos otros materiales ha quedado en el olvido, bien porque los hallazgos fueron expoliados, bien porque el dato es antiguo y se ha perdido, bien porque en su momento no pareció interesante ni recogerlo. Sólo reflejaremos la posibilidad de que ciertos materiales hayan pertenecido a un hallazgo en los casos más obvios, prescindiendo de aquellos que no podemos comprobar.

Son estos registros exactos los testigos fieles de la circulación y por ende del uso de la moneda en Galicia, que indican claramente la procedencia de las piezas, dejando en segundo lugar aquella monetaria de origen desconocido de la cual se podría indicar que pertenecieron a un hallazgo muy probablemente cercano al fondo donde se custodia, así por ejemplo ejemplares de una misma época y muy similares pátinas, sirviendo de materiales de apoyo para nuestra ulterior interpretación. El numario medieval donado o vendido a la institución que lo preserva no nos aporta datos de interés para este trabajo en concreto.

Ha sido la escasa presencia de moneda medieval hallada en Galicia la que incitó nuestra búsqueda, presencia mínima si la comparamos con las decenas de miles de monedas romanas que nos constan halladas por toda la geografía

\footnotetext{
15 Antonio Roma Valdés, Emisiones monetarias leonesas y castellanas de la Edad Media. Organización, economía, tipos y fuentes, [s.1.], Morabetino, 2010.

${ }^{16}$ No todos los materiales se depositan una vez cerrada la excavación, en casos incluso no existe espacio físico en las instituciones destinadas a preservarlos, y quedan en manos de los directores de excavación largo tiempo. Todo ello ralentiza el conocimiento de los nuevos materiales, siendo necesario contactar, en ocasiones, con cada uno de los directores si deseamos actualizar conocimientos.
} 
gallega ${ }^{17}$. Uno de los motivos explicativos de tal proporción pudiera ser la mayor atención dedicada por historiadores y arqueólogos al mundo romano, siendo escasas las intervenciones arqueológicas que se han realizado ad hoc sobre diferentes aspectos del mundo medieval gallego, aunque bien es cierto que existen muchos hallazgos fortuitos de moneda romana, por lo tanto no intencionados, que pudieran quizás hablar de distintos niveles de monetización según qué época.

De entre todos los hallazgos descritos a continuación, muchos aún permanecían inéditos, sumando varios centenares de monedas los ahora reseñados y aún desconocidos. Otros hallazgos sólo se citaban sin concretar el número exacto de piezas y los soberanos identificados, y muchos otros nunca habían sido fotografiados.

Este trabajo nunca habría sido posible sin la buena predisposición de las instituciones que nos abrieron sus puertas, siempre conscientes de la importancia de difundir el conocimiento. Mi más sincero agradecimiento al Museo Arqueológico e Histórico Castelo de San Antón de La Coruña, Museo Provincial de Lugo, Servicio Arqueológico del Concello de Lugo, Museo Diocesano y Catedralicio de Lugo ${ }^{18}$ y Museo Arqueológico Provincial de Orense.

\section{Nuevos hallazgos}

\section{La Coruña: Museo Arqueológico e Histórico Castelo de San Antón ${ }^{19}$}

Iniciamos la revisión de la monetaria custodiada en las principales instituciones museísticas de Galicia advirtiendo que en muchos casos en las colecciones que la conforman ha primado como fuente de ingreso la donación o compra, como es el caso de los fondos que ahora analizamos. Aún así, hallazgos paradigmáticos y las intervenciones arqueológicas de los últimos tiempos han engrosado, para nuestra suerte, los fondos numismáticos de estas instituciones con monedas que, además, sirven como testigo de la historia, por conocerse su lugar de origen, y en el caso de búsquedas intencionadas, su contexto arqueológico. Es para con este museo

\footnotetext{
${ }^{17}$ Ya rondaban los 6000 ejemplares cuando M. Cavada había depositado su Tesis doctoral (sólo el tesoro de Sarandón (Pontevedra) contenía sobre 2000 monedas). Milagros CAVAda Nieto, Galicia romana, circulación monetaria, Santiago de Compostela, Universidad de Santiago de Compostela, 1973, tesis doctoral inédita pero consultable, págs. 21-349. Con este mismo título también existe un breve extracto de la USC.

${ }^{18}$ No describimos aquí la monetaria preservada en esta institución por haber sido aparentemente toda donada. De seguro que detrás de alguna de estas donaciones se esconde algún hallazgo. Sus imágenes y descripción en nuestra Tesis doctoral. Pablo NúÑez Meneses, Historia monetaria de la Galicia medieval, Lugo, Universidad de Santiago de Compostela, tesis doctoral inédita a depositar en la USC.

${ }^{19}$ Mi cálida gratitud al Museo Arqueolóxico e Histórico Castelo de San Antón de A Coruña, a su director José María Bello Diéguez y a su técnico Ana Martínez Arenaz, por su amabilidad y colaboración en la búsqueda tanto del material ya inventariado como del inédito.
} 
ejemplo del primer caso el hallazgo de Muras y del segundo la intervención en la Torre de Hércules, existiendo otros ejemplos pero con muestras más humildes en cuanto a copiosidad (revísense nuestras Tablas del final).

Sorprende que el hallazgo de Muras, relativamente antiguo, copioso y de moneda gruesa, permanezca inédito fuera de las dos instituciones que lo preservan: Museo Arqueológico e Histórico de San Antón y Museo Provincial de Lugo. Los 18 reales de Pedro I preservados en esta primera institución fueron fruto de un depósito del anterior director Armando Durán Cao y nos hace considerar que el hallazgo pudo ser mayor y haber servido, en su momento, en gran parte, al coleccionismo. La catalogación de éstas y las siguientes piezas en nuestras trablas del final.

En las excavaciones de la Torre de Hércules se halló un conjunto amplio de monedas (al menos 18), con tres dineros leoneses de Alfonso IX, un dinero de Sancho IV infante ${ }^{20}$, una pujesa de Alfonso X y un cornado de Alfonso XI (quizás falsificación de época). Otras son monedas fragmentadas y o en mal estado de conservación, entre un conjunto que también contenía moneda romana. Roma Valdés cita dos pujesas y un dinero blanco ${ }^{21}$, suponemos cuando la intervención aún no había sido cerrada.

Algunos nuevos hallazgos serían el de Estaca de Bares, Castelo de Narahío, iglesia de Mosteiro de Monfero, el de Plaza Azcárraga, el de la iglesia de Santiago, el de rúa da Franxa, y el de rúa Santo Domingo, estos cuatro últimos en A Coruña capital, siendo todos hallazgos poco copiosos, con un máximo de cuatro muestras, salvo en el último caso.

En el de Estaca de Bares se hallaron dos dineros, de Alfonso IX y Fernando IV, en Eirexa Vella, encontrados en la excavación dirigida por Felipe Senén López Gómez en Mayo de 1978, y en el Castelo de Naharío una blanca de Enrique III, ceca Burgos (San Sadurniño, A Coruña). En la iglesia de Mosteiro de Monfero (A Coruña), se encontró un cornado de Sancho IV, de ceca coruñesa.

Una pujesa de Alfonso X, se descubrió en la intervención de 1988 en Coliseum C.A. (Plaza Azcárraga) dirigida por Vázquez Gómez, y en ese mismo año, en la intervención de la iglesia de Santiago, se hallaron al menos cuatro monedas: un dinero de seis líneas de Alfonso X, dos ceitiles ${ }^{22}$ de Portugal y una pujesa de

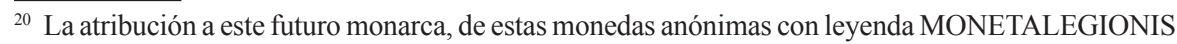
(denominadas en la documentación meajas salamanquesas) se debe a Roma Valdés. Las evidencias parecen indicarlo, aunque en numismática medieval pocas cuestiones están totalmente cerradas.

${ }^{21}$ Antonio Roma Valdés, Emisiones monetarias..., pág. 358.

${ }^{22}$ El ceitil fue una moneda portuguesa creada durante el reinado de Alfonso V de Portugal (14381481), de vellón (el equivalente a las blancas castellanas) valiendo inicialmente la quinta parte del real blanco portugués, aunque en breve se desvalorizó a la sexta e incluso séptima parte a finales
} 
Alfonso X (de un noven y otro dinero de seis líneas no se indica procedencia), y un año después, en 1989, en Rúa da Franxa, se hallaron al menos 3 vellones, uno un leonés de Alfonso IX, otro un óbolo de seis lineas de Alfonso X y un tercero ilegible.

Once vellones medievales se hallaron en la calle Santo Domingo (La Coruña ciudad), entre ellos dos dineros portugueses plenomedievales con severo desgaste como para concretar reinado, un ceitil portugués, un medio tornés portugués de Fernando I tipo torre y ceca A Coruña, un cornado de Enrique II ceca Burgos y dos blancas de Enrique III, ceca Sevilla y la otra ilegible. Otras son monedas modernas, quizás alguna romana y un amplio conjunto de ilegibles.

Como vemos, la moneda portuguesa menuda no puede llegar ya más al norte de Galicia (otro ejemplo también en Lugo ciudad y múltiples en Orense), quedando demostrado que no era tan sólo moneda de frontera y que no sólo las divisas internacionales, esto es, la moneda fuerte, reconocida y de alto valor, era la mejor aceptada en el extranjero. Este tipo de moneda menuda, habitualmente con una cronología que abarca toda la Baja Edad Media y el primer siglo moderno, era ampliamente aceptada por la buena función que desempeñaba como moneda menor utilizada en el pequeño comercio, ante una carestía de numerario menudo en el reino castellano-leonés de la que no sólo dan fe la fuentes documentales, sino también la arqueología. En el Museo de Orense también se halla moneda portuguesa de esta cronología y también plenomedieval, mostrándonos la existencia de contextos circulatorios comunes a varios reinos, en este caso más intensamente en el Sur gallego. Recordemos los pepiones castellanos que tan fuertemente han circulado en el Norte de Portugal. Situación aún más variada en las principales rutas de peregrinación a Compostela, con la llamada moneda del Camino, un contexto circulatorio intenso y diverso que admite como propia la moneda francesa pero también italiana, inglesa, etc ${ }^{23}$. Más al respecto en nuestro Balance del final.

\section{Lugo: Museo Provincial de Lugo ${ }^{24}$}

De entre cientos de monedas romanas aquí custodiadas, hecho en consonancia con la importancia que tuvo Lugo en aquella época y además en concomitancia

del siglo XV. Su acuñación continuará hasta finales del siglo XVI, durante los reinados de Juan II, Manuel I, Juan III y Sebastián I.

${ }^{23}$ Revísense las obras citadas de José Suárez Otero y Antonio Roma Valdés.

${ }^{24}$ Mi afectuoso agradecimiento al Museo Provincial de Lugo y a todo su equipo humano, en especial a su directora Aurelia Balseiro y a sus técnicos María Ofelia Carnero y Enrique Alcorta. Reflexiones compartidas y cuestiones planteadas que han servido para dar luz a una etapa de la Historia de Galicia que se resiste a dejarse ver, el Alto Medievo, en el que estaría inserto el hallazgo de un semidinar 
con otros hallazgos numismáticos de la zona, como los conservados en el Servicio Arqueológico del Concello de Lugo, encontramos medio centenar de ejemplares medievales de gran importancia, como el único ejemplar conocido hasta ahora en Galicia de una moneda del siglo VIII (y además con contexto arqueológico), un semidinar musulmán de Musa ibn Nusair ( 85 H.=704 d.C) acuñado en el Norte de África (alfabeto latino y globo sobre tres gradas en reverso -imagen al final-), hallado en el solar del nuevo Instituto de Enseñanza Media Lugo y a publicar en breve por Cebreiro Ares ${ }^{25}$. Este ejemplar, si no es testigo de la primera incursión musulmana en Galicia, que se dirigió, lógicamente, a su núcleo principal, Lugo, en un momento en el que Compostela, objetivo posterior, aún no existía, es, de seguro, testigo del primer contacto entre el nuevo poder musulmán del Sur y el NO hispano, fuere o no moneda perdida en el momento bélico (ida o vuelta) o debida a una transacción económica poco posterior.

Sobre los trientes visigodos acuñados en Lugo y en Galicia da fe la monetaria conservada ${ }^{26}$, aunque ningún hallazgo hemos encontrado en Lugo provincia. Sobre moneda visigoda hallada en Galicia sólo nos constan los hallazgos de San Cibrián de Lás en Orense (triente de Recaredo I de ceca Eliberri ${ }^{27}$ ), y el de Orense conservado en la RAH (triente de Egica de ceca Gerunda ${ }^{28}$ ). Otra cosa son las monedas de cecas gallegas halladas en la península y fuera de ella ${ }^{29}$.

Junto a este semidinar no aparecen más monedas que hablen de un tesorillo. Inevitablemente se nos viene a la mente la circulación posterior de dirhemes de plata de los que habla la documentación gallega y del $\mathrm{NO}^{30}$, uno y dos siglos más tarde (preludio de la circulación de moneda francesa en Galicia, aunque esta última tremendamente más intensa ${ }^{31}$ ) y nos extraña que aún ninguno se haya encontrado

musulmán del siglo VIII o el Lugo odoariano. La financiación en moneda de la catedral lucense de estas calendas sigue siendo una incógnita. Incluso en la catedral románica nos consta, según indica la documentación, la presencia del pago en especie de una parte notable de los gastos. Lo contrario acontece en Compostela, donde en las obras románicas los pagos en su mayoría son en moneda.

${ }^{25}$ A publicar en breve en el Boletín do Museo Provincial de Lugo por Francisco Cebreiro Ares.

${ }^{26}$ Véase la última síntesis al respecto de Ruth Pliego VÁzQuEZ, "Gallaecia en tiempos del reino visigodo de Toledo", en Francisco Cebreiro Ares (ed.), Introducción a la Historia monetaria de Galicia, s. II a.C.-XVII d.C., A Coruña, Labirinto de Paixóns, 2012, págs. 65-104.

${ }^{27}$ Heiss núm. 12; Pliego núm. 101.e.2. En Ruth Pliego VÁzquez, "Gallaecia en tiempos...”, págs. 65-104.

28 Pliego núm. 668 b.2, 5. Ruth Pliego VÁzQuez, “Gallaecia en tiempos..., págs. 65-104.

${ }^{29}$ Una síntesis sobre los hallazgos de moneda visigoda relacionada con Galicia en: Pablo NúÑEZ Meneses, "Hallazgos de moneda visigoda en Galicia". ANVAR.es (noviembre de 2014) [en línea], disponible en < http://www.anvar.es/2014/11/hallazgos-de-moneda-visigoda-en-galicia/ > [Consulta: 15/12/2015].

${ }^{30}$ Pablo NúÑEz MenESEs, “¿Economía natural...”, págs. 146-155.

${ }^{31}$ Las referencias documentales a moneda francesa en Galicia son innumerables. Un hallazgo ha sido identificado por nosotros entre las monedas halladas en Lugo capital y custodiadas por el Servicio 
en Lugo capital (como sí ha sucedido en Compostela ${ }^{32}$, ya que el de este museo es donado), aunque la arqueología nos va dando continuamente sorpresas (en efecto muchos fueron fundidos para la fabricación de monedas posteriores, como se puede deducir del análisis de los no muchos tesorillos plenomedievales y de las menciones documentales de cada periodo, donde parecen aparecer unas nuevas denominaciones que sustituyen a las anteriores abruptamente, caso también de la moneda de Tours o Anjou ${ }^{33}$ ).

Los catálogos de moneda española dan un salto desde las últimas acuñaciones visigodas hasta las primeras acuñaciones de Alfonso VI, por no conocerse, hasta el momento y después de un siglo de numismática más o menos científica en España ${ }^{34}$, monedas atribuibles a algún poder del Noroeste en este periodo, aunque no encontrar no significa no existir, y no acuñar no significa no circular. Por ello algunos autores han adjetivado este periodo como el de los "siglos sin moneda", refiriéndose a la carencia de moneda coetánea y propia, aunque ello no obsta para que circulasen algunas especies anteriores, aunque nunca plus ultra de comienzos del siglo IX, como mucho (y sólo para con las series visigodas, dentro de lo que permitiese la economía del don ${ }^{36}$ ) u otras foráneas al reino castellano-leonés ${ }^{37}$. Debemos ser cautos con respecto a las menciones documentales que citan unidades de valor de tipo contable entre los siglos IX al XI, existiendo en muchos casos pagos saldados en especie ${ }^{38}$, y con las dificultades que emanan de la circulación de moneda romana en época visigoda, por ejemplo, o de moneda visigoda a alturas del siglo X. Este aspecto ya ha sido desmitificado por Crusafont ${ }^{39}$, entre otros, y ha suscitado polémica entre la comunidad científica que asegura que la

Arqueolóxico del Concello de Lugo. Una síntesis reciente sobre la documentación al respecto en Antonio Roma Valdés, Emisiones monetarias..., págs. 101 y ss.

${ }^{32}$ Al menos dos dirhemes de plata: José SuÁrez Otero, "Conjunto de monedas... págs. 279-283.

${ }^{33}$ Las referencias documentales citadas por Roma Valdés son muchas. Algunas transcripciones en Antonio Roma Valdés, Emisiones monetarias..., págs. 271 y ss.

${ }^{34}$ Son para nosotros algunos precursores: Heiss, Vives, Reinhart, Vázquez Seijas o Bouza Brey. Muy serios son los estudios de Beltrán Villagrasa (y Beltrán Martínez), Mateu y Llopis, Gil Farrés u Orol Pernas . Más allá del ámbito monetario: Sánchez Albornoz, Aguade Nieto, García Álvarez, Loscertales de G. de Valdeavellano o Pastor de Togneri, entre otros. Son muchas las investigaciones al respecto, y aunque la arqueología ofrece sorpresas continuamente, esta cuestión ya tendría que haber salido a la luz.

${ }^{35}$ Pablo NúÑEz Meneses, “¿Economía natural o monetaria...”, págs. 146-155.

${ }^{36}$ Pablo NúÑEZ MeNESES, “¿Economía natural o monetaria...”, págs. 146-155. Interesantísima reflexión sobre la no circulación de moneda tan antigua a alturas del siglo IX o X, la de Miquel Crusafont i SABATER, "Significado y valor del sólido gallecano (s. X-XI)", en Francisco Cebreiro Ares (ed.), Introducción a la Historia... págs. 105-116.

${ }^{37}$ Sobre todo dirhemes del Al-Andalus. La moneda francesa es posterior.

${ }^{38}$ En nuestra Tesis doctoral recogemos cientos de menciones documentales.

${ }^{39}$ Crusafont, entre otras de sus obras: Miquel CRusafont I SABATER, "Significado y valor...”, págs. 105-116. 
arqueología verifica, por ejemplo en el Sur y Levante hispano, la presencia de monedas romanas con monedas hasta visigodas y musulmanes, perviviendo en la circulación, por ello, en varios siglos. En Galicia esto no sucede, al menos por lo que nos desvela la arqueología hasta ahora, no encontrándose moneda romana desde luego en esos estratos del siglo VIII o IX, y cuando aparece con moneda plenomedieval (como en el hallazgo de la Torre de Hércules antes citado) se debe a la mezcolanza de estratos. Aún así, utilizando la lógica, no podemos negar que la moneda visigoda tuviese presencia al menos en todo el siglo VIII, ya que las últimas acuñaciones de dicha monarquía son de inicios de este mismo siglo, caso aparte si circularon siguiendo cauces comerciales (poco probable, al menos en su mayoría, dado su alto valor) o cauces políticos (economía del don, pago de favores, etc).

Por ello, los expertos actuales siguen considerando, a la luz de las monedas conservadas, que el renacer de las acuñaciones plenomedievales se produjo en el reinado de Alfonso VI y, más concretamente, tras la toma de Toledo ${ }^{40}$. Obviando el hecho de que no encontrar no significa no existir, ciertamente ante los datos que poseemos en la actualidad, no podemos afirmar que existan acuñaciones en el $\mathrm{NO}$ en el periodo comprendido entre la última acuñación visigoda y las primeras series de roeles y estrellas de Alfonso $\mathrm{VI}^{41}$, series que presumiblemente también se acuñaron en Lugo (y Compostela), además de la serie posterior del Crismón ${ }^{42}$, ambas con tipología común a las cecas del reino castellano-leonés y, por lo tanto, indistinguibles, al carecer de marcas de ceca específicas.

En el Museo Provincial de Lugo se conservan varios ejemplares de la época de Alfonso VI, aunque son ejemplares donados por German Alonso y desconocemos su origen geográfico. Por ello, a nivel hallazgos, el primer monarca plenomedieval representado en los fondos de este museo es Alfonso IX.

De este reinado se conserva el tesorillo de Buscás ${ }^{43}$ (Ordes, A Coruña), extraordinario tanto por su conservación, como por contener al menos tres meajas compostelanas de extrema rareza, además de trece dineros, todos del tipo de cruz y león a derecha (dineros leoneses en la documentación, como indica Orol

\footnotetext{
${ }^{40}$ Es la tendencia seguida desde Antonio Roma VALDÉs, Moneda y sistemas...

${ }^{41}$ Mozo Monroy, esencialmente, atribuye además a Alfonso VI, otro tipo monetario, como el de la tipología con busto de frente y leyenda ANFVS REX / TOLETA, que Roma Valdés inserta entre las labras de Alfonso VII (Roma número 22). Véase Manuel Mozo Monroy y Francisco Javier García Montes, "Primeras labras de vellón acuñadas en Toledo (ss. XI-XII). Propuesta de interpretación iconográfica", Parva Urbs, 0 (2009), págs. 16-18; y también de los mismos autores, "Aporte histórico y documental sobre el dinero de busto godo de Alfonso VI, rey de León y Castilla", Gaceta Numismática, 180 (2011), págs. 67-82.

${ }^{42}$ Así lo juzgamos tras la lectura del diploma de Fernando II otorgado a esta ciudad de Lugo.

${ }^{43}$ Pablo NúÑez Meneses, "Hallazgo de Ordes del Museo Provincial de Lugo", en XV Congreso Nacional de Numismática, Madrid, Museo Arqueológico Nacional, 2016 [en prensa].
} 
y recuerda Roma $^{44}$ ). Ha sido un tesorillo hasta hace muy poco desconocido, y aún cuando Suárez Otero lo citó en sus obras sobre peregrinación y comercio ${ }^{45}$, no ha sido difundido como se merece. Roma Valdés lo cita en su corpus de hallazgos ${ }^{46}$, pero no cita la existencia de las meajas compostelanas ${ }^{47}$.

Las cecas de estos ejemplares son: Compostela (al menos tres meajas y cinco dineros), Extremadura, Ciudad Rodrigo, León, y ceca vástago y cruz (no asociada todavía a ningún lugar). Debido a los muchos ejemplares existentes sólo insertamos unas imágenes representativas al final.

Es este un tesoro gallego y de moneda gallega (algo no tan habitual ${ }^{48}$ ), atendiendo a las cecas de estos especímenes, que no fue entregado íntegro ya que ante las muy distintas pátinas que observamos en las monedas, su abundancia tuvo que ser mayor. Así, por ejemplo, dos ejemplares presentan verdosidades que, sin embargo, no traspasaron a ningún otro (ni una mota). Careciendo de más información sobre cómo se halló este tesorillo (tipo de contenedor, etc), nada más podemos elucubrar sobre la cantidad de ejemplares monetarios que contenía.

De este mismo reinado (Alfonso IX) es el hallazgo no publicado hasta el momento de cuatro dineros también leoneses encontrados en Gundrame (O Páramo, Lugo), entregados al Museo Provincial de Lugo en 1937 (según el número de registro) y cedidos uno por José Grandío el 20 abril de 1933 y los otros por Vázquez Seijas ${ }^{49}$.

Las cecas son Zamora (o A Coruña, según cada investigador), Compostela (SI enlazadas), L tumbada (probablemente Lugo), y León. Recordamos que las marcas de ceca están a las $3 \mathrm{~h}$ del reverso, entre la cabeza y las patas del león.

Este hallazgo de O Páramo, acaso mayor, confirma que la circulación de moneda llega al rural medieval gallego con cierta cotidianidad. Hallazgos y documentación posterior, sobre todo del siglo XIII en adelante, muestran esta mayor presencia monetaria en el rural gallego, incluso en foros y pago de rentas ${ }^{50}$.

\footnotetext{
${ }^{44}$ Antonio Roma Valdés, Emisiones monetarias... tipo 134 y 135. Véase también Antonio OroL Pernas, Acuñaciones de Alfonso IX, Madrid, Vico, 1982. También Fernando Álvarez Burgos, Catálogo de la moneda medieval castellano-leonesa. Siglos XI al XV, Madrid, Vico-Segarra, 1998.

${ }^{45}$ José SuÁrez Otero, "El tesorillo de Buscás...".

46 Antonio Roma Valdés, Emisiones monetarias..., pág. 334.

${ }^{47}$ Antonio Roma Valdés, Catálogo de las monedas leonesas y castellanas de la Edad Media, [s.1.], Morabetino, 2011, págs. 37-39

${ }^{48}$ Sorprende saber que ante los escasos hallazgos medievales gallegos, no abundan los de moneda gallega, sino de otras cecas del NO peninsular.

${ }^{49}$ Las referencias no son totalmente claras aunque entre un mediano conjunto de monedas de Alfonso IX, donadas, se cita la procedencia de estas cuatro, del pequeño pueblo lucense arriba citado, perteneciente a O Páramo, Lugo.

${ }^{50}$ María Luz Ríos Rodríguez, As orixes do foro na Galicia medieval, Santiago de Compostela, USC, 1993, págs. 84, 148, 158, etc.
} 
De la época inmediatamente posterior (desde Alfonso X a Enrique IV) son más abundantes en esta institución las donaciones de moneda que los hallazgos, siendo un cornado de Sancho IV y tres dineros de Fernando IV de procedencia desconocida. Uno de los del último monarca citado presenta tres agujeros, no relacionados con el mal llamado óbolo de Caronte y tampoco relacionados con la desmonetización de una moneda falsa (este ejemplar es auténtico y además en la moneda falsa el agujereado era central, mucho menos cuidado que en este caso, práctica habitual para desmonetizar moneda al menos desde Alfonso XI). Este caso está relacionado con la moneda usada como elemento ornamental, en telas, vestimentas, e incluso madera ${ }^{51}$, demostrable por la exacta disposición de los tres agujeros, que permiten ver a la perfección el motivo, en este caso el león de reverso. En otros lugares de la península se ha relacionado incluso moneda y joyería ${ }^{52}$. Sobre el culto de pagar a Caronte ${ }^{53}$, tradición de origen griega muy extendida por Roma ${ }^{54}$, presenta muy diversas interpretaciones para los hallazgos medievales, no siempre relacionando el culto a la muerte con la moneda hallada en aquellos contextos. Podía expresar riqueza, pertenencia a un grupo ${ }^{55}$, ser un talismán, querer señalar a un avaro, o simplemente pertenecer a un tesorillo escondido al amparo del espacio sagrado del cementerio ${ }^{56}$. Recordemos que el hecho de no encontrarse las monedas siempre en la misma ubicación indica que no tienen porque estar relacionadas con un ritual común en la península antaño (tradición que es extensible a Europa e incluso Asia $\mathrm{Central}^{57}$ ). En hallazgos medievales pocos ejemplares se introducían en la boca del difunto, como era cotidiano en la Antigüedad, y más bien se ubicaban en el pecho, mano o depositaban en un cuenco en el ajuar ${ }^{58}$. Quizás no era cotidiano que se colgaran del cuello o muñeca si atendemos a que la mayoría de ejemplares relacionados con las necrópolis no se hallaron agujereados aunque es cierto que el contexto funerario es, como

\footnotetext{
${ }^{51}$ Raúl SÁnchez Rincón, Antonio Roma Valdés, "La otra cara de la moneda. Uso y reutilización de la moneda en la Edad Media del Noroeste Peninsular (II)", Numisma, 258 (2015), págs. 143-172.

${ }^{52}$ Especialmente la moneda de Al-Andalus.

${ }^{53}$ Francesca CECI, "La deposizione nella tomba. Continuità di un rito tra paganesimo e cristianesimo", Historia Antiqua, 13 (2005), págs. 407-416.

${ }^{54}$ Raimon Graells I Fabregat, "Sobre el primer culto a Caronte en noreste de la península Ibérica, datos para su discusión”, Gallaecia, 32 (2013), págs. 21-45.

${ }^{55}$ Renata CANTILENA, “Un obolo per Caronte?", Caronte, un obolo per l'ldilà. Pdp, 50, III-VI (1995), págs. 165-177.

${ }^{56}$ Raúl SÁnChez Rincón, Antonio Roma Valdés, “La otra cara...”, págs. 143-172.

${ }^{57}$ Stanislaw Suchodolski, "Les débuts de l'obole des défunts en Europe centrale au haut Moyen Age", Acta Numismàtica, 21-22-23 (1993), págs. 347-354.

58 Investigaciones de Alicia Arévalo GonzÁlez, Diario de Ibiza (10 febrero 2012) [en línea], disponible en < http://www.diariodeibiza.es/pitiuses-balears/2012/02/10/alicia-arevalo-muerte-humano-conservador/536489.html $>$ [Consulta: 07/01/2016].
} 
ya indicaba Mercedes Rueda ${ }^{59}$ (y parece confirmarse en otras épocas y espacios geográficos) un lugar muy fructífero para encontrar monedas. El patinado de estas tres piezas es tan distinto que nos impide afirmar que se hallasen juntas, y de haberlo hecho, faltarían monedas.

Recordemos que los catálogos clásicos han asociado algunas de estas monedas con el reinado de Fernando III y aún las series MONETACASTELLE / ET:LEGIONIS (hoy atribuidas a Alfonso X), como también las series MONETALEGIONIS (hoy atribuidas a Sancho IV, aún infante) ${ }^{60}$. Es curioso, aunque cierto, que al gran rey Santo (Fernando III) quien da un fuerte impulso a la reconquista, no se le pueden atribuir, hasta el momento, monedas a su nombre, aunque monedas de monarcas anteriores siguieron acuñándose, demostrable por algunas referencias documentales y el estudio de cuños de diversas series.

Siete ejemplares de Alfonso XI (4 nóvenes y 3 cornados) son también de procedencia desconocida.

De la época de Pedro I es todo un tesorillo, el de Muras (Lugo), conservándose aquí 32 reales de plata del tipo P coronada. Otros ejemplares, como hemos visto, se custodian en el museo coruñés de San Antón, demostrando que es este un hallazgo partido, y que muchos ejemplares pudieron acabar en manos privadas.

Del vencedor de la guerra fraticida, el primero de los Trastámara ${ }^{61}$, Enrique II, tenemos un cruzado de origen desconocido.

Una dobla de la Banda de Juan II se ha encontrado en la plaza Mayor de Viveiro (Viveiro, Lugo), cuyo ingreso al museo se produjo en 2001 (sondajes de Emilio Ramil González, resolución de 1997). Esta moneda se halló junto con otras 56 monedas, muchas modernas y muchas otras ilegibles, un total de 57 monedas incluyendo la dobla.

Nos ha sorprendico la escaseza de moneda foránea pleno y bajomedieval hallada en Lugo (por el momento sólo un dinero de Tours custodiado en el Servicio Arqueológico del Concello de Lugo -véase más abajo-), siendo una moneda de Alfonso V de Aragón (I de Mallorca, 1416-1458) de procedencia desconocida.

\footnotetext{
${ }_{59}$ Mercedes Rueda Sabater, Primeras acuñaciones de Castilla y León, Salamanca, Junta de Castilla y León y Asociación Española de Arquología Medieval, 1991.

${ }^{60}$ Antonio Roma VAldés, Emisiones... pág. 236.

${ }^{61} \mathrm{Su}$ título le viene de su padre adoptivo, que alude al río Tambre: Tras Tamaris.
} 


\section{Lugo: Monedas medievales del Servicio Arqueológico del Concello de Lugo $^{62}$}

De entre las más de 4.000 monedas halladas en Lugo ciudad en las últimas décadas (preservadas en el Servicio Arqueológico del Concello de Lugo), tan sólo once son medievales, número similar a las monedas modernas y contemporáneas, siendo la inmensa mayoría romanas, lo que nos indica no sólo la fuerte impronta que ha dejado el mundo romano en la ciudad más antigua de Galicia, sino también lo poco que se ha centrado la arqueología en el mundo medieval de Lugo.

De entre las monedas medievales asemeja que aparecen siempre los dineros del noveno leonés o los cornados de Sancho IV y Alfonso XI, por otro lado, monedas que han tenido una producción millonaria y que han llegado a la mayoría de bolsillos de la época dado su escaso valor (las que más han monetizado la sociedad y han servido al pequeño comercio). Estas muestras suelen encontrarse de forma separada, no perteneciendo ningún conjunto a algo que se pudiera denominar tesorillo (es moneda perdida, no tesaurizada). Han aparecido en intervenciones que se centraban en el mundo romano, por lo que no debe extrañarnos que en casos aparezcan con moneda romana, en ningún caso porque hubieran compartido contexto circulatorio alguno (700 años de diferencia, a lo mínimo, entre unas y otras monedas), sino porque Lugo, ciudad viva en constante cambio, con una fuerte cristianización del espacio ya desde la llamada época odoriana y sobre todo en la plenitud medieval, ha alterado (rotura de la isostasia), destruido o mezclado estratos que fueron de muy diversas épocas (por ello también aparece moneda moderna y hasta contemporánea de Francisco Franco).

Sobresale, por ser la primera vez que aparece en Lugo, un dinero de la abadía de Tours, además de una moneda no identificada (no sólo por su sumo desgaste sino por lo poco común en hallazgos del Noroeste peninsular) que al presentar cruz tanto en anverso como en reverso nos lleva a la idea de ser probablemente un styca de Northumbria ${ }^{63}$, siendo, si fuera el caso, la primera vez que aparecería en Galicia, una vez que se comprobó que los compostelanos son dineros posteriores, como ha demostrado Suárez Otero ${ }^{64}$.

\footnotetext{
${ }^{62}$ Mi más afectuoso agradecimiento al Servizo Arqueolóxico do Concello de Lugo y a todo su equipo humano, así como a todos los directores de excavación que nos permitieron ver los fondos numismáticos: Antonio Rodríguez Colmenero, Enrique González Fernández, Covadonga Carreño Gascón, Francisco M. Hermes Raigoso.

63 Agradecemos a Manuel Mozo Monroy el apunte de esta posibilidad, planteando a su vez amplias dudas. También a Miguel Domínguez y Ruth Pliego, quienes también la examinaron descartando finalmente que pudiera tratarse de una moneda visigoda falsa de época.

${ }^{64}$ José SuÁrez Otero, “La moneda en el edículo apostólico...”, págs. 275-279.
} 
Tres son los dineros de Alfonso IX, dos del tipo árbol (moneta regis en la documentación) de ceca dos roeles, y uno tipo león (legionense en la documentación), encontrados en tres calles diferentes de Lugo ciudad (más información en nuestras Tablas).

Otro es un dinero seisén de Alfonso X (también de vellón) tipo Monetacastelle / etlegionis (también llamado noven), de ceca ilegible al estar partido.

Dos monedas son cornados, uno de Sancho IV (vellón) de ceca dos estrellas (ceca aún no atribuida a ningún lugar), y otro de Alfonso XI.

De Juan II es un blanca de vellón, de ceca posiblemente venera (A Coruña), y de Enrique IV un cuartillo de vellón de ceca Burgos.

Aparece también un ceitil portugués, de vellón (sexta parte de real) y un dinero de Tours, por el módulo plenomedieval.

Una última moneda no ha sido todavía catalogada con total exactitud debido a su severo desgaste y a la inusitada rareza de esta tipología, máxime si ello lo aplicamos a los hallazgos comunes localizados en el Noroeste peninsular. De un lado, Roma Valdés apunta que pudiera tratarse acaso de un dinero carolingio indeterminado (véase fotografía de esta pieza al final del texto); de otro, Mozo Monroy, argumenta -pese a los escasos elementos gráficos que en ella se pueden vislumbrar- que de acuerdo a su tipología anglosajona y al trazado epigráfico de las pocas letras que se pueden discernir en ellas (apenas varios grafemas "I", una "O" y una "V" en anverso; y una posible " $\mathrm{X}$ " en reverso), podría tratarse de una "styca"65, labrada en el reino de Northumbria en la segunda mitad del siglo IX, en la que tan sólo se representa para ambas caras el símbolo duplicado de la cruz cristiana exenta de terminaciones potenzadas, posiblemente atribuible a Raedwulf o a Aelle II, o incluso a el rey Aethelredo II. Ante estas evidencias podríamos hablar del único hallazgo, hasta el momento, de una moneda datada en el oscuro siglo IX en todo el Noroeste peninsular, una vez que Suárez Otero descartó que en la catedral compostelana se hallaran monedas carolingias (realmente son monedas francesas posteriores, con una tipología que continuó en varios siglos). Hasta el momento sólo es Lugo ciudad el único caso en el que aparece tanto una moneda datada en el siglo VIII (semidinar arriba expuesto) como otra fechada en el IX.

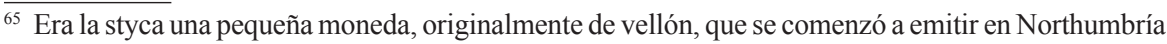
a finales del siglo VIII y hasta mediados del IX, aunque permaneció en circulación hasta la conquista viquinga de Northumbría en el año 867.
} 


\section{Orense: Museo Arqueolóxico Provincial de Orense $e^{66}$}

Hemos accedido a la descripción de 285 monedas medievales, curiosamente muchas con procedencia conocida, destacando por cantidad el tesoro de Monte Rego, con 149 monedas, recientemente publicado ${ }^{67}$.

La actual actividad arqueológica ha recuperado muchas monedas medievales, generalmente muestras separadas, no tesorillos. Antes de describirlas, hacemos notar la existencia, a mayores, de dos conjuntos de entre las monedas con procedencia desconocida o donadas, que pudieran haber pertenecido a hallazgos próximos, dado el similar lustre y pátina de las mismas. Se trata de un conjunto de veintisiete monedas de Tours, y otro amplio conjunto de monedas portuguesas: dos de Alfonso III, una de Dinis I, una de Juan I, quince de Alfonso V, tres de Manuel I, y seis ilegibles.

Sobre la circulación de moneda portuguesa en zona de frontera (y en cierta distancia) de Pontevedra y Orense, da fe, además, la documentación medieval gallega. Quedan testimonios arqueológicos de hallazgos de dichas monedas incluso tan lejos como en Lugo y La Coruña ciudades.

Es, hasta el momento, el tesoro de Monte Rego, el conjunto más amplio de moneda medieval hallado en Galicia, y el que por ello más honestamente merece este nombre; consta de ciento cuarenta y nueve monedas halladas en Monte Rego, Cudeiro, Orense ${ }^{68}$. En su publicación pueden verse imágenes de las monedas, contenedor y contextualización arqueológica. Comprende 16 dineros burgaleses de Alfonso VIII, 71 dineros leoneses de Alfonso IX (alguno compostelano), 50 dineros de seis líneas de Alfonso X, 1 óbolo de seis líneas de Alfonso X, 4 cornados de Sancho IV ( 1 coruñés), 3 dineros de Fernando IV (todos del tipo castillo en anverso y león en reverso), 1 cornado y 1 dinero (noven) de Alfonso XI, y 2 cornados de Juan I.

Hallazgos de moneda medieval preservados en esta institución y aún no publicados, serían:

Dos monedas portuguesas en Orense ciudad, rúa Progreso 24, con desgaste severo que sólo nos permitió distinguir de un lado armas portuguesas, de otro castillo sobre mar. Como ya hemos indicado, la catalogación aparece en nuestras tablas del final.

\footnotetext{
${ }^{66} \mathrm{Mi}$ afectuoso agradecimiento al Museo Arqueolóxico Provincial de Orense y a todo su equipo humano, en especial a su director Julio Rodríguez y a su técnico Belén Lorenzo, por su afabilidad y predisposición.

${ }^{67}$ Purificación Rodríguez García, Francisco Fariña Busto, “Acubillo de Monte Rego”, Boletín Auriense, 44 (2014), págs. 217-266.

${ }^{68}$ Ibidem.
} 
Un ceitil portugués de Alfonso V, hallado en Allariz, Orense.

En Castro Formigueiro, Trasalba, Orense, se han hallado un dinero de Enrique II de gráfila cuadrada, un dinero de Alfonso X, y un dinero de Dinis I de Portugal.

En la comarca de Valdeorras, Orense, se encontraron un dinero de Enrique II similar al anterior y una blanca de Juan II.

En el Castillo de Araúxo, Lobios, Orense, se hallaron 21 monedas medievales: una moneda totalmente borrosa, por el módulo un dinero; otra de igual modo y además doblada; un dinero de Enrique II de rombo o gráfila cuadrada; dos dineros de Alfonso III de Portugal; dos dineros de Dinis I de Portugal; tres vellones de Juan I de Portugal; dos ceitiles de Alfonso V de Portugal; un cornado de Juan I; cuatro blancas de rombo de Enrique IV (tres de ceca La Coruña); y un dinero de Tours.

No nos debe extrañar la circulación de moneda portuguesa en zonas de Galicia, más en las sureñas fronterizas, como el caso de Lobios. Documentalmente también se justifica esta circulación y existen muchos otros hallazgos en Galicia.

En la rúa Hernán Cortés, número 38-40, Orense, se halló una moneda de vellón de mala conservación, por la figura del león un cortadillo español, quizás de Felipe II, y por lo tanto ya moneda moderna.

En la calle San Miguel, 6, Orense, el inventario hace constar la existencia de tres monedas, aunque sólo vemos dos, de hecho en una bolsita, ilegibles, y en rúa Porta Nova de Abaixo número 5, Ribadavia (San Domingos) se cita una moneda, sin mayor concreción.

En el edificio del Museo de Orense, desde hace años en remodelación, se hallaron doce monedas: dos dineros de Alfonso III de Portugal o de Dinis I, una tercera pieza, partida, asemeja de igual cronología; un ceitil portugués de Juan III (ya moneda moderna). De entre las monedas castellanas una es un dinero leonés de Alfonso IX, otra asemeja un dinero de Alfonso X, una tercera un dinero de seis líneas o de la guerra de Alfonso X y una cuarta una pujesa de este mismo monarca; otra moneda, de vellón y módulo mayor, es ilegible; en un dinero se distingue el tipo castillo y león y orla circular, aunque con leyendas totalmente ilegibles; dos monedas son de gráfila polilobulada, que por el módulo asemejan blancas de Enrique III o Juan II.

En la necrópolis rupestre de San Vítor, Barxacova, Parada de Sil, Orense, se hallaron cuatro monedas: real de Enrique II; dinero de Fernando I de Portugal; ceitil de Alfonso V de Portugal; cornado de Sancho IV.

En la capilla de Santa Catarina, Reza Vella, Santiago das Caldas, Orense, se halló un dinero de vellón del siglo XIII, la imagen se corresponde con un vellón portugués, por error, por lo que no la reflejamos aquí.

En la Iglesia de Santa Mariña, Xinzo de Limia, Orense, se encontró otro vellón portugués de la misma época que el anterior. 
En Aquae Querquennae, Porto Quintella, Bande, Orense, se halló otro vellón portugués de similar cronología y en el castro Coto do San Trocado, San Amaro, O Carballiño, Orense, se encontró un ceitil portugués del siglo XV o XVI. Insertamos imágenes representativas al final de nuestro texto, y toda la información necesaria en nuestras tablas.

Se cita un hallazgo compostelano en esta institución, con un dinero de Alfonso VI, ingresado en 1957 por Chamoso Lamas, aunque no se encuentra el ejemplar. Suponemos que puede ser alguno de los hallados en la catedral compostelana y ya citado (o no) por Suárez Otero.

\section{Pontevedra: Museo Provincial de Pontevedra}

Aún no nos han dado fecha de acceso para consultar a los fondos numismáticos de este museo.

\section{BALANCE}

La revisión de las principales instituciones museísticas gallegas era un trabajo por hacer que podía aportar datos de sumo interés, como de hecho ha ocurrido, más conociendo los escasos hallazgos gallegos de moneda medieval publicada, insuficientes para mensurar el impacto de la moneda en la sociedad gallega medieval.

Nuevos hallazgos sueltos y aún algún conjunto ha salido a la luz, y las nuevas intervenciones cada vez depositan mayor material numismático con lo que, por suerte, el caudal de conocimientos aumenta, suceso además muy necesario.

Otras instituciones no se citan en este trabajo, ya que sus fondos numismáticos han sido ya publicados, total o parcialmente ${ }^{69}$, caso de la monetaria de la Universidad de Santiago de Compostela ${ }^{70}$, o del Museo de las Peregrinaciones y de Santiago ${ }^{71}$. Otras, como museos catedralicios y episcopales, o municipales

\footnotetext{
${ }^{69}$ En algunas ocasiones son más las monedas donadas o compradas que las procedentes de hallazgos o intervenciones arqueológicas. Son éstas segundas las que nos transmiten verdadera información sobre el uso, circulación y función de la moneda. Aún así, algunos registros antiguos pueden esconder antiguos hallazgos que quedaron en el olvido, como indica Suárez en el caso de algunas monedas custodiadas en la USC.

${ }^{70}$ Algunas referencias sobre moneda plenomedieval propia y foránea relacionada con la peregrinación a Compostela, y aún bajomedieval, en: José SuÁrez Otero, "Aproximación á colección arqueolóxica da Universidade de Santiago", en Gallaecia Fulget: (1495-1995): Cinco séculos de historia universitaria, Santiago de Compostela, 1995, págs. 476-479. Del mismo autor: "Arqueología y Peregrinación. La moneda en la Peregrinación marítima a Santiago", en Actas del II Congreso Internacional de Estudios Jacobeos: rutas atlánticas de peregrinación a Santiago de Compostela: Ferrol, septiembre de 1996, Santiago de Compostela, 1998, págs. 197-218.

${ }^{71}$ José María de Francisco Olmos, Feliciano Novoa Portela, Catálogo de numismática do Museo das Peregrinacións e de Santiago, Santiago de Compostela, Xunta de Galicia, 2009.
} 
(como el museo numismático de Lobios), contienen en gran medida moneda donada, o moneda sin referencia alguna. Algunas citas a sus monedas en nuestra Tesis doctoral, aún inédita.

Ante los datos arriba expuestos y aunque son muchos los nuevos descubrimientos, en ningún caso se comparan con los hallazgos gallegos de moneda romana ${ }^{72}$, no siendo la causa la existencia de una mayor monetización en época romana (dependería del periodo medieval), ya que, por ejemplo, nadie dudaría que en la Edad Moderna o Contemporánea la sociedad estaba plenamente monetizada y, sin embargo, los hallazgos son mucho menores que los de época medieval, es más, cuanto más reciente es el periodo de estudio menos hallazgos parece que encontramos. La causa radica en que las intervenciones analizadas no se centraban sobre el mundo ni moderno ni contemporáneo, incluso en casos ni medieval, de ahí estas proporciones. La moneda romana parece salir siempre, especialmente del Bajo Imperio, acuñada por millones en algunos $\operatorname{casos}^{73}$, como también lo fue alguna serie de Alfonso VI, Alfonso IX o bajomedieval. Sabido es de lo fortuito de los hallazgos, sueltos o en conjunto, con lo que toda interpretación siempre está sujeta a hándicaps. Como indicaba Doménech ${ }^{74}$, trabajamos con lo que ha llegado hasta nosotros, moneda perdida o no recuperada cuyo antiguo propietario en ningún caso querría este destino, es decir, su deseo sería el de recuperar siempre sus ahorros. Sobre la mezcolanza entre monedas de muy distintas épocas, remitimos a lo dicho supra, consideramos que se debe a la misma mezcolanza de estratos, no a la coexistencia de contextos circulatorios comunes (así por ejemplo moneda romana con plenomedieval).

Como sabemos, son escasos en Galicia los tesoros de moneda, frente a los múltiples de época romana, siendo el más cuantioso en cuanto a ejemplares el de Monte Rego (Orense). Por ello debemos prestar suma atención a los datos que nos aportan los pequeños tesorillos y hallazgos de moneda suelta, monedas últimas que aparentemente no pudieron ser tesaurizadas, sino perdidas. Pero incluso los hallazgos sueltos de moneda medieval no son abundantes en esta región, y aunque es de intuir, como ocurre en otras épocas y lugares ${ }^{75}$, que parte de las antiguas

\footnotetext{
${ }_{72}$ A nivel peninsular los hallazgos medievales tampoco son de lo más abundante, si bien existen tesorillos paradigmáticos que incluso han servido para confirmar o cambiar seriaciones convencionales.

${ }^{73}$ Ya rondaban los seis millares aproximadamente en la Tesis inédita de Cavada Nieto de 1973, números de difícil confirmación por haber sido muchos tesorillos antiguos expoliados. En la actualidad los hallazgos suman al menos el doble de ejemplares (sólo en el Servicio Arqueológico del Concello de Lugo se conservan varios miles de monedas romanas halladas en Lugo ciudad en los años 80 y 90).

${ }^{74}$ Carolina Doménech Belda, "Moneda y espacios de poder en el mundo visigodo. Los trémises de El Tolmo de Minateda (Hellín, Albacete), Arqueología y territorio medieval, 21 (2014), págs. 9-38. ${ }^{75}$ Es notable el acercamiento al coleccionismo que se dá, ante los escasos hallazgos, en el estudio de la moneda sueva, por ejemplo. Mario Gomes Marques, A moeda peninsular...
} 
colecciones de moneda gallega y no gallega provienen de antiguos hallazgos e incluso de tesorillos cuyo origen no fue tenido en consideración, debemos primar la cautela, ya que no es mensurable y el coleccionismo en Galicia permanece en este sentido muy inédito ${ }^{76}$. ¿Cómo ha llegado la moneda no actual al coleccionismo? Pues a través del coleccionismo mismo o a través de hallazgos. Colecciones museísticas antiguas de un mismo periodo asemejan tener la misma morfología, no se descarta que pudieran proceder de un mismo conjunto, primando la cautela, como ya hizo para con las caetra lucenses Vázquez Seijas ${ }^{77}$. Las donaciones son un caso similar, a veces incluso indicando que el origen de sus monedas es un hallazgo por todos conocido (caso de Muras, Lugo).

Volviendo a hablar del coleccionismo, es una herramienta útil, aunque debemos primar la prudencia para respaldar ciertas cuestiones como la abundancia de determinadas series monetarias y, por ende, su impacto en la sociedad. ¿Cuántas monedas únicas se conocen tan sólo a través del coleccionismo? Éste se hace especialmente importante en aquellos periodos cuando los hallazgos están bajo mínimos, caso de la moneda de época sueva. No nos podemos olvidar de la documentación de toda esta época, en ocasiones fecunda en datos, no sólo mencionando monedas, sino su uso, la manera en que se conocían en la época, su contenido metálico, ratio entre monedas, equivalencia moneda-producto, etc.

Como hemos ido viendo, la moneda está armónicamente imbricada en todo proceso histórico, escaseando en los siglos oscuros, reapareciendo (y fuertemente) en la Plena Edad Media y mutiplicando sus formas y valores en la Baja Edad Media. Ciudad-economía-moneda sería el trinomio que mejor hablaría de la expansión plenomedieval, con la Iglesia como centro económico y político, la que promovía las más grandes y principales obras de la ciudad y aún fuera de ella, con el gasto y uso de dinero que ello conlleva. Aunque la moneda participó escasamente en estas obras de ingeniería precoces del siglo IX ó X (así en la época odoriana lucense), nadie duda que las obras románicas se financiaron en gran parte en moneda, como justifica por ejemplo la diplomática compostelana, aunque en Lugo la documentación aún habla sobre la posible escaseza de moneda, y dado el caso, sobre el complementar el pago en especie de parte de los grandes salarios, así por ejemplo del maestro Raimundo ${ }^{78}$.

Con la apertura de Galicia a Europa gracias al Camino de Santiago, penetra la moneda francesa, sobre todo desde el siglo XII en adelante, con gran impacto de la moneda de Tours y la de Anjou, ésta última con Lugo como su


de sus monedas (lugar del hallazgo), no la dan a conocer.

77 Manuel VÁzquez Seijas, "De re numismatica", Boletín de la Comisión Provincial de Monumentos Históricos y Artísticos de Lugo, Tomo II, n. 17-18 (1940), págs. 186-188.

${ }^{78}$ Documentos transcritos en nuestra Tesis doctoral.
} 
máximo exponente, atendiendo a la documentación. Su pronta desaparición de las menciones diplomáticas indica que pudo haber sido recogida y fundida para la acuñación de las nuevas series de moneda de la monarquía castellano-leone$\mathrm{sa}^{79}$. Algo similar se desprende de la arqueología, cuando abruptamente desaparecen los hallazgos de moneda de Tours. Aún así, y atendiendo sobre todo a la arqueología (la documentación también se pronuncia al respecto), ha sido de tanta importancia el impacto de la moneda portuguesa en la Galicia bajomedieval como la de la francesa en la plenomedieval. La moneda da testimonio de ello, como de la importancia de la Compostela de Gelmírez, hasta ahora la única que arqueológicamente halla dineros de Alfonso VI, teniendo que esperar para con el resto de Galicia hasta el noveno leonés, salvo contadas excepciones con moneda de Fernando II.

Entonces, estas monedas medievales halladas en diversos lugares de Galicia, ¿qué nos transmiten y qué función han tenido? Primeramente debemos decir que, salvo contadas excepciones, son monedas pequeñas y de escaso valor, de vellón, dineros y sus divisores (meajas u óbolos), en su mayoría, de los siglos XII en adelante, con una concentración de moneda, ahora de valor medio, desde mediados del XIV hasta el fin de la Edad Media. En consonancia con el crecimiento demográfico y económico, la sociedad exigió nueva moneda para utilizar en los mercados, y la autoridad política, la monarquía, enterada de esa necesidad, labró nueva moneda, menuda primero, para nutrir a los nacientes burgos y ferias que, por otro lado, junto a las ciudades y puertos, eran potenciados y protegidos por la misma monarquía ${ }^{80}$. Por lo tanto, la función de esta moneda era esencialmente comercial, sin negar (sería un craso error) una función fiscal obvia, que fue la que agilizó la acuñación de estas series por la monarquía, para servir a su propósito, medir la riqueza, captar impuestos y saldar las deudas con su cada vez más creciente administración y ejército.

El uso de estas monedas tuvo que ser habitual, atendiendo a la abundancia de muchas de estas denominaciones en el coleccionismo, y sobre todo en los hallazgos y tesorillos de Galicia y del Noroeste. Como indican muchos investigadores tras analizar los diferentes cuños de cada serie, se estima que muchas de ellas tuvieron producciones millonarias y, por lo tanto, un claro impacto en la sociedad y economía de la época, potenciando su monetarización. Desde luego, de entre los ejemplares que se han encontrado en Galicia, en casi todos los fondos museísticos gallegos existen dineros de Alfonso IX, Cornados de Sancho IV, y aún reales de Pedro I. Debido a esto se deduce que estas series han tenido gran-

\footnotetext{
$\overline{79}$ Así lo deducimos de arqueología y documentación. Esta postura ya expuesta en Antonio RomA VALDÉs, Emisiones monetarias..., págs. 101 y ss.

${ }^{80}$ De ahí las exenciones fiscales, cartas y fueros que conocemos documentalmente.
} 
des tiradas (además de por ser las más comunes en el coleccionismo) ${ }^{81} \mathrm{y}$, como pensamos, si en algún momento del Medievo podemos decir que el proceso de monetarización del rural gallego estaba en estado muy avanzado es, desde luego, a partir del gobierno del IX de León. Al menos ya en el siglo XIII aparece el pago de foros y rentas en moneda, y el campesino que se lo podía permitir, vendía en el mercado sus excedentes a cambio de moneda ${ }^{82}$.

En cuanto a las monedas halladas no íntegras en algunos fondos, a la vista está que no han sido partidas ex professo, sino que así se encontraron debido a los estragos del paso del tiempo. De ningún modo debemos pensar que fueron partidas para fraccionar la moneda, como aconteció en época romana o en Al-Andalus; esta función ya la tenían las meajas, óbolos o medios dineros. En cuanto a los pequeños bronces hallados de pequeño módulo asemejan, cuando son legibles, moneda romana. No debemos atribuir los ilegibles a nada que se le parezca a los llamados bronces o platas visigodos, cuyos hallazgos se concentran en el Sur y Este hispano, acuñados probablemente por autoridades locales, de forma consentida, suponemos, por parte de la monarquía, y por lo tanto no moneda nacional, entendida como moneda labrada por la monarquía visigoda, aunque sí con tipología similar. Además estos llamados nummi aún son de proporciones más pequeñas, algunos de menos de cinco milímetros. Nada que se pueda asimilar a las mal llamadas platas y bronces visigodos hemos encontrado en los fondos numismáticos gallegos que hemos revisado (sólo en el Servicio Arqueológico del Concello de Lugo hemos revisado unas cuatro mil monedas, casi en su totalidad romanas, y entre ellas con preeminencia de moneda bajoimperial).

Esta recopilación de nuevos hallazgos, junto a los ya sintetizados por Roma Valdés ${ }^{83}$ y anteriormente Rueda y Sáez ${ }^{84}$, e interrelacionando los grandes y pequeños tesoros que se conocen para con el Noroeste, ayuda a mostrar un estado de la cuestión del uso y función de la moneda en Galicia, visión aún incompleta debido a los aún escasos ejemplares procedentes de hallazgos, pese a los casi doscientos que ahora publicamos. Con todo se pueden establecer algunas conclusiones:

1) La mayoría de las monedas pertenecen a hallazgos fortuitos, no a labores arqueológicas intencionadas.

\footnotetext{
${ }^{81}$ Hecho ratificado, por otro lado, por los análisis de los cuños existentes, que nos deja entrever la tirada monetaria aproximada, si bien, quizás, los diez mil ejemplares por pareja de cuños sea cifra algo elevada. Excelente reflexión al respecto en R. Pliego VÁzQuez, La moneda visigoda... págs. 195 y ss.

${ }^{82}$ María Luz Ríos Rodríguez, As orixes do foro..., en varios documentos citados. Este hecho era común a Europa: Georges Duby, Economía rural y vida campesina en el Occidente medieval, Barcelona, Península, 1973.

83 Antonio Roma Valdés, Emisiones monetarias..., págs. 343-359.

${ }^{84}$ Mercedes Rueda SAbater e Inmaculada SÁez SÁiz, "Hallazgos medievales de moneda castellana y leonesa", Numisma, 230 (1992), págs 205-260.
} 
2) Se trata de pequeñas muestras, escasean los tesorillos.

3) Sobre todo en referencias antiguas, se intuye que parte de los hallazgos acabaron en manos privadas.

4) Se comprueba arqueológicamente la presencia de moneda francesa, tan citada en la documentación gallega plenomedieval, que antaño era escasa fuera de lo que era el entorno de Compostela y el Camino.

5) Se comprueba que las monedas más abundantes en el coleccionismo lo son también en los hallazgos.

6) Se ha dado relativamente poca importancia a la moneda portuguesa cuando es tremendamente citada en la documentación gallega bajomedieval, y aparece ahora también en múltiples hallazgos. La moneda portuguesa es en el Bajo Medievo lo que la francesa en la Plena Edad Media.

7) Asemejan existir diferencias circulatorias a nivel provincial, y aunque la muestra es insuficiente, la moneda portuguesa es más frecuente en Orense (el Museo de Pontevedra permanece sin revisar), como la de la invasión portuguesa en A Coruña. Estas diferencias se podrían dar también a nivel local: centros económicos como puertos, ciudades comerciales, paradas en el Camino, era núcleos estratégicos con gran afluencia de gente, comercio y moneda. El Camino de Santiago era además una ruta de penetración de moneda a la par que motor económico. Toda circunstancia histórica influye en la circulación y uso de la moneda.

8) Los hallazgos que engloban múltiples reinados nos transmiten las relaciones circulatorias existentes entre diferentes monedas, la ausencia repentina de ciertas tipologías encubre posibles desmonetizaciones, nos hablan de la presencia de la moneda fuerte propia o foránea, etc.

Hacemos notar que aún queda mucho por hacer, mucho material arqueológico aún no está depositado, las intervenciones se están multiplicando y cada escaso tiempo aparecen ejemplares inéditos y hallazgos paradigmáticos que van a completar en gran medida esta recopilación e, incluso, cambiar nuestra concepción sobre la moneda medieval en Galicia. La Historia no es estática, nosotros tampoco debemos serlo.

\section{IMÁGENES}

Sólo insertamos algunas imágenes representativas, ampliadas sin guardar proporción. Para conocer la metrología de las monedas y visualizar todas las imágenes consúltese nuestra Tesis doctoral ${ }^{85}$.

\footnotetext{
${ }_{85}$ Pablo NúÑ̃Ez Meneses, Historia monetaria....
} 
1) Hallazgo de Eirexa Vella, Estaca de Bares (A Coruña), preservado en el Museo Arqueolóxico de San Antón.


2) Hallazgo de Castelo de Narahío (San Sadurmiño, A Coruña) ${ }^{86}$ :
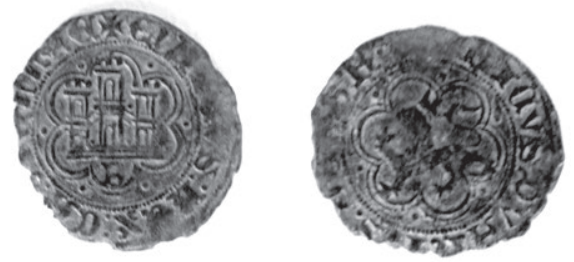

3) Semidinar hallado en Lugo capital y conservado en el MP-Lugo.


4) Dobla de la Banda de Juan II hallada en Viveiro y conservado en el MP-Lugo.
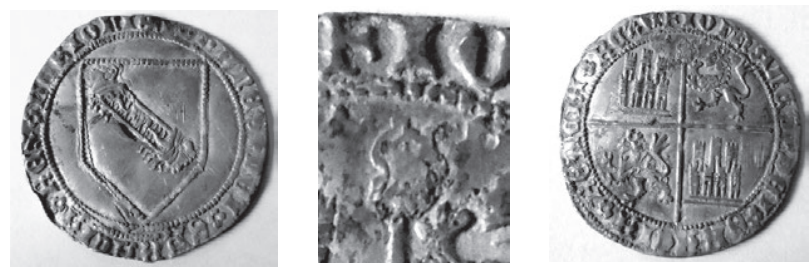

\footnotetext{
${ }^{86}$ Imágenes cortesía del Museo Arqueolóxico e Histórico de San Antón de A Coruña.
} 
5) Dinero de Tours hallado en Lugo ciudad y preservado en el Servicio Arqueolóxico do Concello de Lugo.
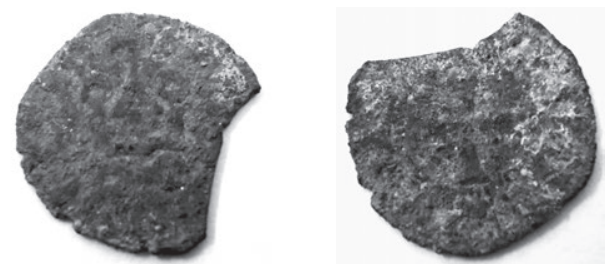

6) ¿Styca de Northumbria? Hallado en Lugo ciudad y preservado en el Servicio Arqueolóxico do Concello de Lugo.
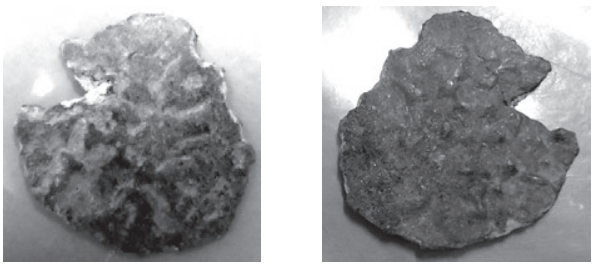

7) Hallazgo de Castro Formigueiro, Trasalba, Ourense, preservado en el Museo Arqueolóxico Provincial de Ourense ${ }^{87}$.
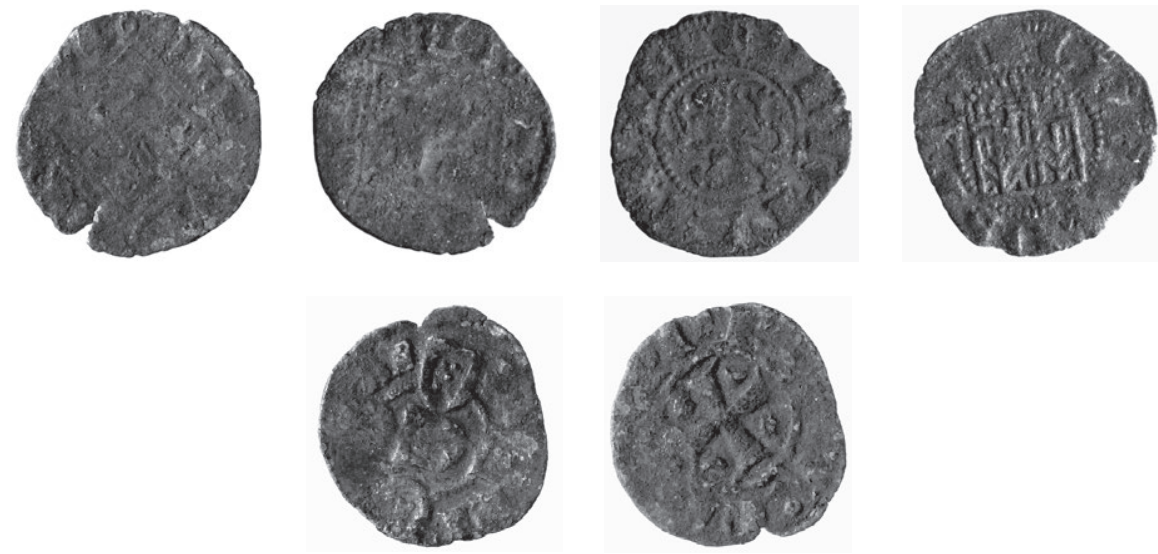

${ }^{87}$ Estas imágenes y las siguientes son cortesía del Museo Arqueolóxico Provincial de Ourense. 
8) Hallazgo de la necrópolis rupestre de San Vítor, Barxacova, Parada de Sil, Ourense, preservado en el Museo Arqueolóxico Provincial de Ourense.

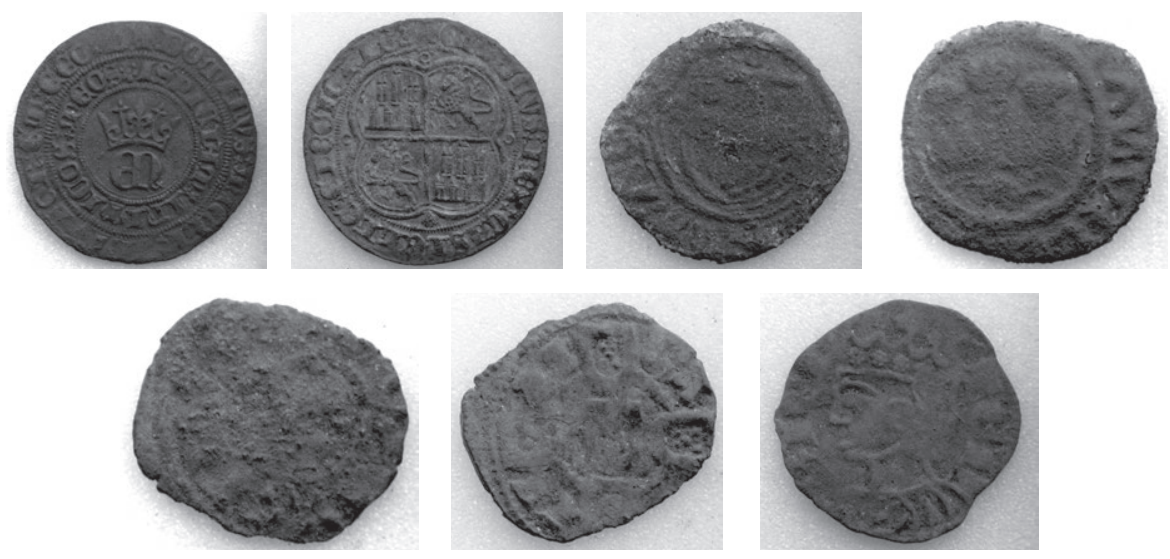

TABLAS

Tabla 1. Monedas medievales de procedencia registrada.

Museo Arqueológico e Histórico de San Antón, La Coruña.

\begin{tabular}{|l|l|l|l|l|}
\hline Inventario & Moneda & Principales catálogos & Excavación & Procedencia \\
\hline 845 & $\begin{array}{l}\text { Real de Pedro I, } \\
\text { de ceca La Coruña }\end{array}$ & $\begin{array}{l}\text { Roma tipo 23688. Paz tipo 228-24689; } \\
\text { CAvón tipo 1287-12900; } \\
\text { Álvarez Burgos tipo 377-380.691. }\end{array}$ & Muras?92 \\
\hline 846 & Idem & Ibídem & & Muras? \\
\hline 847 & Idem & Ibídem & & Muras? \\
\hline 848 & Idem, variante en leyendas & Ibídem & Muras? \\
\hline
\end{tabular}

\footnotetext{
${ }^{88}$ Antonio Roma Valdés, Catálogo de las monedas leonesas y castellanas de la Edad Media, [s.1.], Morabetino, 2011.

${ }^{89}$ Jaime PaZ Bernardo, Moedas galegas: moedas, medallas, billetes: especializado do século IX a.C. ó século XXI d.C., Barcelona, Numismática J. Paz, 2002.

${ }^{90}$ Adolfo CAYÓN, Clemente CAYÓN, Juan CAYÓN, Las monedas españolas: del tremis al euro. Vol. 2: del 411 a nuestros días, Madrid, Cayón-Jano, 2005.

${ }^{91}$ Fernando Álvarez Burgos, Catálogo de la moneda medieval castellano-leonesa. Siglos XI al $X V$, Madrid, Vico-Segarra, 1998.

${ }^{92}$ Se cita en la ficha de este número y los siguientes como moneda comprada por Armando Durán Cao, director en su día de esta institución, aunque no se hace referencia expresa a su procedencia del hallazgo de Muras, como sí acontece en los siguientes casos.
} 


\begin{tabular}{|c|c|c|c|c|}
\hline Inventario & Moneda & Principales catálogos & Excavación & Procedencia \\
\hline 849 & Idem & Ibídem & & Muras? \\
\hline 850 & Idem & Ibídem & & Muras? \\
\hline 851 & Idem & Ibídem & & $\begin{array}{l}\text { Depositado por } \\
\text { Armando Durán } \\
\text { Cao, hallazgo de } \\
\text { Muras, Lugo. }\end{array}$ \\
\hline 852 & Idem & Ibidem & & Ibídem \\
\hline 853 & Idem & Ibidem & & Ibídem \\
\hline 854 & Idem & Ibidem & & Ibídem \\
\hline 855 & Idem & Ibidem & & Ibídem \\
\hline 856 & Idem & Ibidem & & Ibídem \\
\hline 857 & Idem & Ibidem & & Ibídem \\
\hline 858 & Idem & Ibidem & & Ibídem \\
\hline 859 & Idem & Ibidem & & Ibídem \\
\hline 860 & Idem & Ibidem & & Ibídem \\
\hline 861 & Idem & Ibídem & & Ibídem \\
\hline 862 & Idem & Ibidem & & Ibídem \\
\hline 863 & Idem & Ibidem & & Ibídem \\
\hline 864 & Idem & Ibidem & & Ibídem \\
\hline 865 & Idem & Ibidem & & Ibídem \\
\hline 866 & Idem & Ibídem & & Ibídem \\
\hline 867 & Idem & Ibidem & & Ibídem \\
\hline 868 & Idem & Ibidem & & Ibídem \\
\hline 1221 & $\begin{array}{l}\text { Dinero de Alfonso IX, } \\
\text { hallado en Santiago } \\
\text { de Bares. }\end{array}$ & $\begin{array}{l}\text { Roma 134; Paz 139-154; } \\
\text { Álvarez Burgos 121-136; } \\
\text { Cayón 1081-1090 }\end{array}$ & $\begin{array}{l}\text { Felipe Senén López } \\
\text { Gómez, exc. } \\
\text { Maio } 1978 .\end{array}$ & $\begin{array}{l}\text { Bares, } \\
\text { Eirexa Vella. }\end{array}$ \\
\hline 1222 & $\begin{array}{l}\text { Dinero de Fernando IV, } \\
\text { de ceca Burgos, hallado } \\
\text { en el mismo lugar. }\end{array}$ & $\begin{array}{l}\text { Roma 215; } \\
\text { Álvarez Burgos 319; } \\
\text { Cayón 1217-1226 }\end{array}$ & $\begin{array}{l}\text { Felipe Senén López } \\
\text { Gómez, } \\
\text { exc. Maio } 1978 .\end{array}$ & $\begin{array}{l}\text { Bares, } \\
\text { Eirexa Vella. }\end{array}$ \\
\hline 2649 & $\begin{array}{l}\text { Pujesa de Alfonso X, } \\
\text { hallada en Plaza Azcárraga }\end{array}$ & $\begin{array}{l}\text { Roma 209; Álvarez Burgos 280; } \\
\text { Cayón 1160-1173 }\end{array}$ & $\begin{array}{l}\text { Xunta/ } \\
\text { Vázquez Gómez }\end{array}$ & $\begin{array}{l}\text { Plaza de } \\
\text { Azcárraga, } \\
\text { La Coruña }\end{array}$ \\
\hline $4370-1$ & $\begin{array}{l}\text { Cornado de Sancho IV, } \\
\text { ceca La Coruña. }\end{array}$ & $\begin{array}{l}\text { Roma 211; Paz 185; } \\
\text { Álvarez Burgos 297; Cavón } 1183\end{array}$ & \begin{tabular}{|l} 
Interv. \\
Arqueológica, 2005
\end{tabular} & $\begin{array}{l}\text { Iglesia de } \\
\text { Mosteiro de } \\
\text { Monfero } \\
\text { (La Coruña) }\end{array}$ \\
\hline 4624 & $\begin{array}{l}\text { Blanca de Enrique III, } \\
\text { ceca Burgos }\end{array}$ & Álvarez Burgos 597; Cayón 1492 & $\begin{array}{l}\text { Sondaxes en Castelo } \\
\text { de Narahío (San Sa- } \\
\text { durmiño, A Coruña). }\end{array}$ & $\begin{array}{l}\text { Código CD 102A } \\
2006 / 693-0\end{array}$ \\
\hline
\end{tabular}




\begin{tabular}{|c|c|c|c|c|}
\hline Inventario & Moneda & Principales catálogos & Excavación & Procedencia \\
\hline \multirow[t]{18}{*}{$\begin{array}{l}\text { UE1582 } \\
\text { 001 TH92 } \\
-56\end{array}$} & Leonés de Alfonso IX & $\begin{array}{l}\text { Roma 134; Paz 139-154; } \\
\text { Álvarez Burgos 121-136; } \\
\text { Cayón 1081-1090 }\end{array}$ & $\begin{array}{l}\text { Excavaciones } \\
\text { Torre de Hércules }\end{array}$ & $\begin{array}{l}\text { Torre de } \\
\text { Hércules }\end{array}$ \\
\hline & Cornado Alfonso XI & Roma 220; sim. CaYón 1234-1255 & Exc. T. Hérc. & \begin{tabular}{|l} 
Torre \\
de Hércules
\end{tabular} \\
\hline & Fragmento & & Exc. T. Hérc. & \begin{tabular}{|l} 
Torre \\
de Hércules
\end{tabular} \\
\hline & Dinero real de Alfonso IX & Roma 132. & Exc. T. Hérc. & \begin{tabular}{|l} 
Torre \\
de Hércules
\end{tabular} \\
\hline & $\begin{array}{l}\text { Moneta Legionis, } \\
\text { de Sancho IV infante }\end{array}$ & Roma 210 & Exc. T. Hérc. & \begin{tabular}{|l|} 
Torre \\
de Hércules
\end{tabular} \\
\hline & $\begin{array}{l}\text { Pujesa de Alfonso } X, \\
\text { fragmentado }\end{array}$ & $\begin{array}{l}\text { Roma 209; Álvarez Burgos 280; } \\
\text { Cavón 1160-1173 }\end{array}$ & Exc. T. Hérc. & $\begin{array}{l}\text { Torre de } \\
\text { Hércules }\end{array}$ \\
\hline & Ilegible & & Exc. T. Hérc. & \begin{tabular}{|l} 
Torre \\
de Hércules
\end{tabular} \\
\hline & llegible? & & Exc. T. Hérc. & \begin{tabular}{|l} 
Torre \\
de Hércules
\end{tabular} \\
\hline & Dinero leonés de Alfonso IX & $\begin{array}{l}\text { Roma 134; Paz 139-154; } \\
\text { Álvarez Burgos 121-136; } \\
\text { Cayón 1081-1090 }\end{array}$ & Exc. T. Hérc. & \begin{tabular}{|l} 
Torre \\
de Hércules
\end{tabular} \\
\hline & Ilegible? & & Exc. T. Hérc. & \begin{tabular}{|l} 
Torre \\
de Hércules
\end{tabular} \\
\hline & $\begin{array}{l}\text { Ilegible y partida; } \\
\text { moderna? }\end{array}$ & & Exc. T. Hérc. & \begin{tabular}{|l} 
Torre \\
de Hércules
\end{tabular} \\
\hline & Leonés de Alfonso IX & $\begin{array}{l}\text { Roma 134; Paz 139-154; } \\
\text { Álvarez Burgos 121-136; } \\
\text { Cayón 1081-1090 }\end{array}$ & Exc. T. Hérc. & \begin{tabular}{|l|} 
Torre \\
de Hércules
\end{tabular} \\
\hline & $\begin{array}{l}25 \text { monedas, en su } \\
\text { mayoría romanas, } \\
\text { muchas ilegibles }\end{array}$ & & Exc. T. Hérc. & \begin{tabular}{|l} 
Torre \\
de Hércules
\end{tabular} \\
\hline & Ilegible & & Exc. T. Hérc. & \begin{tabular}{|l} 
Torre \\
de Hércules
\end{tabular} \\
\hline & Ilegible & & Exc. T. Hérc. & \begin{tabular}{|l} 
Torre \\
de Hércules
\end{tabular} \\
\hline & Ilegible & & Exc. T. Hérc. & \begin{tabular}{|l} 
Torre \\
de Hércules
\end{tabular} \\
\hline & Ilegible & & Exc. T. Hérc. & \begin{tabular}{|l|} 
Torre \\
de Hércules
\end{tabular} \\
\hline & Ilegible & & Exc. T. Hérc. & \begin{tabular}{|l} 
Torre \\
de Hércules
\end{tabular} \\
\hline
\end{tabular}




\begin{tabular}{|c|c|c|c|c|}
\hline Inventario & Moneda & Principales catálogos & Excavación & Procedencia \\
\hline TR $91 / 5-26$ & Ilegible & & Rúa da Franxa 1989 & $\begin{array}{l}\text { La Coruña, } \\
\text { Rúa da Franxa }\end{array}$ \\
\hline TR $91 / 5-30$ & Leonés de Alfonso IX & Álvarez Burgos 121-136 & Rúa da Franxa 1989 & $\begin{array}{l}\text { La Coruña, } \\
\text { Rúa da Franxa }\end{array}$ \\
\hline TR 91/5-22 & $\begin{array}{l}\text { Óbolo de seis lineas } \\
\text { de Alfonso X }\end{array}$ & Álvarez Burgos 247 & Rúa da Franxa 1989 & $\begin{array}{l}\text { La Coruña, } \\
\text { Rúa da Franxa }\end{array}$ \\
\hline IS-88 & Ceitil, quizás de Alfonso V & A. GOMES 06.03-16.01 & Año 1988 & $\begin{array}{l}\text { Iglesia de } \\
\text { Santiago, } \\
\text { La Coruña }\end{array}$ \\
\hline \multirow[t]{2}{*}{ IS-88 } & $\begin{array}{l}\text { Dinero de seis líneas de } \\
\text { Alfonso } X\end{array}$ & Roma 199; Álvarez Burgos 227-246 & & $\begin{array}{l}\text { Iglesia de } \\
\text { Santiago }\end{array}$ \\
\hline & Pujesa & Roma 209 & & $\begin{array}{l}\text { Iglesia de } \\
\text { Santiago }\end{array}$ \\
\hline $\begin{array}{l}\text { TR } 91 \\
\text { /5-27A }\end{array}$ & $\begin{array}{l}\text { Dinero de seis líneas de } \\
\text { Alfonso } X\end{array}$ & Roma 199; Álvarez Burgos 227-246 & & $\begin{array}{l}\text { Iglesia de } \\
\text { Santiago }\end{array}$ \\
\hline TR $91 / 5-2$ & Ceitil, quizás de Alfonso V & A. GOMES 06.03-16.01 & & $\begin{array}{l}\text { Iglesia de } \\
\text { Santiago }\end{array}$ \\
\hline TR 91/5-38 & Ceitil & & & \\
\hline IS-88 & Ceitil & & & \\
\hline IS-88 z: 240 & $\begin{array}{l}\text { Óbolo de seis lineas } \\
\text { Cornado de Juan II } \\
\text { Pepión de Fernando IV, } \\
\text { de entre un total de } 23 \\
\text { monedas. }\end{array}$ & & & \\
\hline 4487 & $\begin{array}{l}11 \text { vellones medievales, } \\
\text { entre ellos } 2 \text { dineros } \\
\text { plenomedievales } \\
\text { portugueses, } 1 \text { ceitil } \\
\text { portugués y un medio } \\
\text { tornés portugués de } \\
\text { Fernando I tipo torre, } \\
1 \text { cornado de Enrique III y } \\
2 \text { blancas de Enrique III; } \\
\text { otras son monedas } \\
\text { modernas, quizás alguna } \\
\text { romana y un amplio } \\
\text { conjunto de ilegibles. }\end{array}$ & $\begin{array}{l}\text { Respectivamente: los dos dineros } \\
\text { portugueses como muy temprano } \\
\text { son de Sancho II (aunque esta } \\
\text { tipología sigue hasta Fernando I); } \\
\text { el ceitil portugués quizás de } \\
\text { Alfonso V (A. Gomes 06.03-16.01); } \\
\text { el medio tornés portugués de } \\
\text { Fernando I tipo torre A. Gomes } \\
55.01 \text {; el cornado de Enrique II } \\
\text { ceca Burgos RomA 261; } \\
\text { Álvarez Burgos 486; CAYón } \\
\text { 1379-1390; y las dos blancas de } \\
\text { Enrique III (Cayón 1492-1503). }\end{array}$ & $\begin{array}{l}\text { Intervención } \\
\text { arqueológica. } \\
\text { Xunta: CJ 102A } \\
\text { 2005/404-0. }\end{array}$ & $\begin{array}{l}\text { Calle Santo } \\
\text { Domingo, } 6 \\
\text { (La Coruña). }\end{array}$ \\
\hline
\end{tabular}


Tabla 2. Monedas medievales de procedencia registrada. Museo Provincial de Lugo.

\begin{tabular}{|c|c|c|c|c|}
\hline Inventario & Moneda & Principales catálogos & Excavación & Procedencia \\
\hline 1666 & Semidinar & & $\begin{array}{l}\text { Instituto Enseñanza } \\
\text { Media de Lugo. } \\
\text { Registro: 1255 } \\
\text { (3-abril-1944). }\end{array}$ & $\begin{array}{l}\text { Lugo, nuevo } \\
\text { Instituto de } \\
\text { Enseñanza } \\
\text { Media }\end{array}$ \\
\hline $\begin{array}{l}1646-1662 ; \\
1666-1667\end{array}$ & $\begin{array}{l}13 \text { dineros y } 3 \text { meajas de } \\
\text { Alfonso IX, del tipo leonés, } \\
\text { al menos tres meajas } \\
\text { compostelanas, entre } \\
\text { otros dineros. }\end{array}$ & $\begin{array}{l}\text { Dineros: Roma 134, Álvarez Burgos } \\
\text { 121-136, Cayón 1081-1092; } \\
\text { meajas: Roma 135, Álvarez Burgos } \\
\text { 138, Cayón } 1093 \text { (ninguno cataloga } \\
\text { la meaja compostelana). }\end{array}$ & & $\begin{array}{l}\text { Buscás, Ordes, } \\
\text { La Coruña }\end{array}$ \\
\hline $\begin{array}{l}1642, \\
1644-1645, \\
1656\end{array}$ & $\begin{array}{l}4 \text { dineros leoneses } \\
\text { de Alfonso IX }\end{array}$ & $\begin{array}{l}\text { Roma 134, Álvarez Burgos 121-136, } \\
\text { Cayón 1081-1092 }\end{array}$ & & $\begin{array}{l}\text { Gundrame, } \\
0 \text { Páramo, } \\
\text { Lugo }\end{array}$ \\
\hline 1721 & Cornado de Sancho IV & & & Desconocida \\
\hline $1670-1672$ & 3 dineros de Fernando IV & & & Desconocida \\
\hline $\begin{array}{l}1709-1711, \\
1322, \\
1723-1724\end{array}$ & $\begin{array}{l}4 \text { novenes y } 3 \text { cornados } \\
\text { de Alfonso } \mathrm{XI}\end{array}$ & & & Desconocida \\
\hline $\begin{array}{l}\text { 1675-1681, } \\
\text { 1708 lote }\end{array}$ & 32 reales de Pedro I. & $\begin{array}{l}\text { Roma 236, Álvarezz Burgos 400-407.1 y } \\
\text { Cayón 1306-131 }\end{array}$ & & Muras, Lugo \\
\hline 1715 & Cruzado Enrique II & & & Desconocida \\
\hline 1714 & $\begin{array}{l}\text { Dobla de la Banda de } \\
\text { Juan II }\end{array}$ & Álvarez Burgos 617.1; Cayón 1515. & & $\begin{array}{l}\text { Plaza Mayor de } \\
\text { Viveiro (Lugo), } \\
\text { ingreso año } \\
2001 .\end{array}$ \\
\hline \multirow[t]{2}{*}{1673} & Blanca de Juan II & & & Desconocida \\
\hline & Cuartillo de Enrique IV & & & Desconocida \\
\hline 1726 & $\begin{array}{l}\text { Diner de Alfonso V de } \\
\text { Aragón (ceca Mallorca) }\end{array}$ & & & Desconocida \\
\hline
\end{tabular}


Tabla 3. Monedas medievales de procedencia registrada.

Servicio Arqueológico del Concello de Lugo.

\begin{tabular}{|c|c|c|c|c|}
\hline Inventario & Moneda & Principales catálogos & Excavación & Procedencia \\
\hline $\mathrm{CC} / 88$ & $\begin{array}{l}\text { Dinero de Alfonxo IX, } \\
\text { tipo árbol }\end{array}$ & $\begin{array}{l}\text { Roma 132-M. Paz tipo } 136 . \\
\text { Cayón 1091-1092 }\end{array}$ & $\begin{array}{l}\text { 1988. Directora: } \\
\text { Covadonga Carreño } \\
\text { Gascón. }\end{array}$ & $\begin{array}{l}\text { Lugo ciudad, } \\
\text { rúa Clérigos, }\end{array}$ \\
\hline AR $133 / 1$ & $\begin{array}{l}\text { Dinero de Alfonxo IX, } \\
\text { tipo árbol }\end{array}$ & $\begin{array}{l}\text { Roma 132-M. Paz tipo } 136 . \\
\text { CaYón 1091-1092 }\end{array}$ & $\begin{array}{l}\text { 1990. Director: } \\
\text { Fco. M. Herves } \\
\text { Raigoso. }\end{array}$ & $\begin{array}{l}\text { Lugo ciudad, } \\
\text { rúa Armanyá, } \\
\text { no } 13 .\end{array}$ \\
\hline AR 862 & $\begin{array}{l}\text { Dinero de Alfonso IX, } \\
\text { tipo león }\end{array}$ & $\begin{array}{l}\text { Roma 134. Paz tipo 139-154. } \\
\text { Cayón 1081-1090. } \\
\text { Álvarez Burgos tipo } 121 .\end{array}$ & $\begin{array}{l}\text { 1986. Director: } \\
\text { Antonio Rodríguez } \\
\text { Colmenero. }\end{array}$ & $\begin{array}{l}\text { Lugo ciudad, } \\
\text { rúa Armanyá, } \\
\text { no } 10 .\end{array}$ \\
\hline AR $133 \mathrm{~A} 2$ & Dinero seisén de Alfonso $X$ & $\begin{array}{l}\text { Roma 207. Cayón 1145-1156. } \\
\text { Álvarez Burgos tipo } 261 .\end{array}$ & $\begin{array}{l}\text { 1990. Director: } \\
\text { Fco. M. Herves } \\
\text { Raigoso. }\end{array}$ & $\begin{array}{l}\text { Lugo ciudad, } \\
\text { rúa Armanyá, } \\
\text { nº } 13 .\end{array}$ \\
\hline LU86/SD & Cornado de Sancho IV & $\begin{array}{l}\text { Roma 211-10. Paz tipo 185-192. } \\
\text { Cayón 1195. Álvarez Burgos 304.1. }\end{array}$ & $\begin{array}{l}\text { 1986. Director: } \\
\text { Antonio Rodríguez } \\
\text { Colmenero. }\end{array}$ & $\begin{array}{l}\text { Lugo ciudad, } \\
\text { Plaza de Sto. } \\
\text { Domingo. }\end{array}$ \\
\hline \multirow[t]{2}{*}{ LU91/PL } & Cornado de Alfonso XI & $\begin{array}{l}\text { Roma 220-5a. Cayón } 1244 . \\
\text { Álvarez Burgos tipo } 338 .\end{array}$ & $\begin{array}{l}\text { 1991. Director: } \\
\text { Entrique González } \\
\text { Fernández. }\end{array}$ & $\begin{array}{l}\text { Lugo ciudad, } \\
\text { Pazo Lomas } \\
\text { (Rúa Nova, } \\
\text { no 19). }\end{array}$ \\
\hline & Blanca de Juan II & $\begin{array}{l}\text { Álvarez Burgos 626. Paz } 334 . \\
\text { Cayón } 1524 .\end{array}$ & & Lugo ciudad. \\
\hline $\begin{array}{l}\text { LU91/ } \\
\text { PL. AB }\end{array}$ & Cuartillo de Enrique IV & $\begin{array}{l}\text { Cayón 1630. Álvarez Burgos } 739 . \\
\text { Paz tipo 351-354. }\end{array}$ & $\begin{array}{l}\text { 1991. Director: } \\
\text { Entrique González } \\
\text { Fernández. }\end{array}$ & $\begin{array}{l}\text { Lugo ciudad, } \\
\text { Pazo Lomas } \\
\text { (Rúa Nova, } \\
\text { no 19). }\end{array}$ \\
\hline \multirow[t]{2}{*}{$\begin{array}{l}\text { CR18 } \\
\text { (UE 1001) }\end{array}$} & Ceitil portugués & $\begin{array}{l}\text { Total desgaste de las leyendas, } \\
\text { aunque la emisión comienza con } \\
\text { Alfonso V (A. Gomes tipo 06-03, } \\
\text { pág. 125-129). }\end{array}$ & $\begin{array}{l}\text { 1995. Director: } \\
\text { Entrique González } \\
\text { Fernández. }\end{array}$ & $\begin{array}{l}\text { Lugo ciudad, } \\
\text { Rúa da Cruz, } \\
\text { n0 } 18 .\end{array}$ \\
\hline & \begin{tabular}{|l|} 
Dinero de Tours \\
plenomedieval
\end{tabular} & & & Lugo ciudad \\
\hline RE88 7 a 3 & $\begin{array}{l}\text { ¿Styca del siglo IX de } \\
\text { Northumbria? }\end{array}$ & & $\begin{array}{l}\text { 1988. Director: } \\
\text { Covadonga Carreño } \\
\text { Gascón. }\end{array}$ & $\begin{array}{l}\text { Lugo ciudad, } \\
\text { Rúa Raíña, no } 7 .\end{array}$ \\
\hline
\end{tabular}


Tabla 4. Monedas medievales de procedencia registrada.

Museo Arqueológico Provincial de Orense.

\begin{tabular}{|c|c|c|c|c|}
\hline Inventario & Moneda & Principales catálogos & Metrología & Procedencia \\
\hline DX0088/9 & $\begin{array}{l}2 \text { vellones portugueses, } \\
\text { asemejan ceitiles }\end{array}$ & $\begin{array}{l}\text { La emisión comienza con Alfonso V } \\
\text { (A. Gomes tipo 06-03, pág. 125-129). }\end{array}$ & & $\begin{array}{l}\text { Orense, rúa } \\
\text { Progreso, } 24 . \\
\text { Colegio Josefinas }\end{array}$ \\
\hline DX0088/12 & Idem & Ibídem & & Ibídem \\
\hline $\begin{array}{l}\text { CE001177 } \\
- \text { CE001329 }\end{array}$ & 149 monedas & $\begin{array}{l}\text { Comprende } 16 \text { dineros burgaleses } \\
\text { de Alfonso VIII, } 71 \text { dineros leoneses } \\
\text { de Alfonso IX (alguno compostela- } \\
\text { no), } 50 \text { dineros de seis líneas de } \\
\text { Alfonso X, } 1 \text { óbolo de seis líneas de } \\
\text { Alfonso X, } 4 \text { cornados de Sancho IV } \\
\text { (1 coruñés), } 3 \text { dineros de Fernan- } \\
\text { do IV (todos del tipo castillo en } \\
\text { anverso y león en reverso), } \\
1 \text { cornado y } 1 \text { dinero (noven) de } \\
\text { Alfonso XI, y } 2 \text { cornados de Juan I. }\end{array}$ & & $\begin{array}{l}\text { Monte Rego, } \\
\text { Cudeiro, Orense }\end{array}$ \\
\hline CE004220 & $\begin{array}{l}\text { Ceitil de Alfonso V de } \\
\text { Portugal. Tres torres sobre } \\
\text { muralla bañada por mar; } \\
\text { reverso escudo con } 5 \\
\text { quinas dispuestas en } \\
\text { forma de cruz cantonada } \\
\text { de castillos. }\end{array}$ & A. Gomes tipo 06-03, pág. 125-129 & 19 mm.; 1,6 gramos & $\begin{array}{l}\text { Allariz, Maceda, } \\
\text { comarca. }\end{array}$ \\
\hline CE005579 & $\begin{array}{l}\text { Enrique Il, vellón. ENRICVS } \\
\text { REX CA, castillo de tres } \\
\text { torres, debajo B, en gráfila } \\
\text { cuadrada; Reverso ENRICVS } \\
\text { REX LEG, león a izquierda, } \\
\text { B entre patas, gráfila cua }\end{array}$ & Roma 263; Álvarez Burgos tipo 493 & $17 \mathrm{~mm} . ; 0,8 \mathrm{~g}$. & $\begin{array}{l}\text { Castro } \\
\text { Formigueiro, } \\
\text { Coto do Castello. } \\
\text { Trasalba, } \\
\text { Amoeiro, } \\
\text { Orense. }\end{array}$ \\
\hline CE005580 & $\begin{array}{l}\text { Alfonso X, ALF REX } \\
\text { CASTELLE, castillo dentro } \\
\text { de gráfila circular, debajo S; } \\
\text { ET LEGIONIS, leónn ram- } \\
\text { pante a izquierda dentro de } \\
\text { gráfila de puntos circular. }\end{array}$ & Roma 201; Álvarez Burgos tipo 248 & $17 \mathrm{~mm} ., 0,7 \mathrm{~g}$. & Ibídem \\
\hline CE005582 & $\begin{array}{l}\text { Dinis I, (D REX PORTUGAL), } \\
\text { cruz cantonada de estrellas } \\
\text { y luna. AL (GA RB II) cinco } \\
\text { quinas en cruz. J. Ferraro } \\
\text { VAz y Javier SALGADo, Livro } \\
\text { de moedas de Portugal, } \\
\text { Braga, Livraria Cruz, 1969, } \\
\text { pág. 45, no. 4?. }\end{array}$ & A. Gomes tipo 01.01, págs. 77-78 & $15 \mathrm{~mm} ., 0,6 \mathrm{~g}$. & Ibídem \\
\hline
\end{tabular}




\begin{tabular}{|c|c|c|c|c|}
\hline Inventario & Moneda & Principales catálogos & Metrología & Procedencia \\
\hline $\begin{array}{l}\text { CE006020 } \\
/ 53\end{array}$ & $\begin{array}{l}\text { Enrique II, ENRICVS REX CA, } \\
\text { castillo dentro de gráfila } \\
\text { cuadrada; ENRICVS REX LEG } \\
\text { león a izquierda dentro de } \\
\text { similar gráfila. }\end{array}$ & Roma 263 & $17 \mathrm{~mm} ., 0,6 \mathrm{~g}$. & $\begin{array}{l}\text { Valdeorras, } \\
\text { comarca, } \\
\text { Orense. }\end{array}$ \\
\hline $\begin{array}{l}\text { CE006020 } \\
/ 68\end{array}$ & $\begin{array}{l}\text { Juan II, IOHANIS DEI GRACIA, } \\
\text { debajo venera. Castillo } \\
\text { dentro de gráfila lobular. } \\
\text { Reverso IOHANES DEI } \\
\text { GRACIA REX, leon a } \\
\text { izquierda dentro de la } \\
\text { misma gráfila. }\end{array}$ & $\begin{array}{l}\text { Álvarez Burgos tipo 624; } \\
\text { Paz tipo } 334\end{array}$ & $21 \mathrm{~mm} ., 1,7 \mathrm{~g}$. & Idem \\
\hline DX0002/2 & Moneda portuguesa & & 25 mm., 1,52 gr. & $\begin{array}{l}\text { Castelo de } \\
\text { Araúxo=Castelo } \\
\text { da Vila. Araúxo, } \\
\text { Lobios, Ourense. }\end{array}$ \\
\hline DX0010/3 & $\begin{array}{l}\text { Vellón de gráfilas } \\
\text { cuadradas. }\end{array}$ & Roma 263; Álvarez Burgos tipo 493 & & Idem \\
\hline DX0016/61 & $\begin{array}{l}\text { Ceitil de Alfonso V, castillo } \\
\text { de tres torres y muralla } \\
\text { bañada por mar, Reverso } \\
\text { REX... Escudo con cinco } \\
\text { quinas en cruz, cantonado } \\
\text { de castillos. }\end{array}$ & A. Gomes tipo 06.03 , págs $125-129$ & 22 mm., $2,2 \mathrm{~g}$. & Idem \\
\hline DX0016/62 & Idem & Ibidem & $22 \mathrm{~mm} ., 1,4 \mathrm{~g}$. & Idem \\
\hline DX0016/63 & $\begin{array}{l}\text { Dinero de Dinis I, (D:REX) } \\
\text { PORT(TVGL) cruz cantonada } \\
\text { con estrella en primer y } \\
\text { cuarto cuartel y luna en el } \\
\text { segundo y tercero. Reverso } \\
\text { (...) cuatro quinas irregula- } \\
\text { res. A. GomEs, Moedas Portu- } \\
\text { guesas, Lisboa, Associaçao } \\
\text { Numismática de Portugal, } \\
\text { 2001, pág. } 77 \text {. } \\
\end{array}$ & A. Gomes tipo 01.01 , págs. $77-78$ & 17 mm., 0,4 g. & Idem \\
\hline DX0016/64 & Idem & & $18 \mathrm{~mm} ., 0,8 \mathrm{~g}$. & Idem \\
\hline DX0016/65 & $\begin{array}{l}\text { Dinero de Alfonso Ill de } \\
\text { Portugal, (AL)FONSVS REX, } \\
\text { cruz cantonada con luna } \\
\text { en primer y cuarto cuartel } \\
\text { y estrella en los restantes. } \\
R P O(R T) V G(A L) \text {, cinco } \\
\text { quinas en cruz. }\end{array}$ & & 16 mm., 0,8 g. & \\
\hline
\end{tabular}




\begin{tabular}{|c|c|c|c|c|}
\hline Inventario & Moneda & Principales catálogos & Metrología & Procedencia \\
\hline DX0016/67 & Idem & & $18 \mathrm{~mm} ., 0,7 \mathrm{~g}$. & Idem \\
\hline DX0016/68 & $\begin{array}{l}\text { Cornado de Juan I, } \\
\text { IOHAN(IS) REX, busto coro- } \\
\text { nado a izquierda, rompiendo } \\
\text { leyenda. CASTELLEE } \\
\text { LE(GI)ONI(S), castillo, BS a } \\
\text { los lados de torre central, } \\
\text { debajo B. }\end{array}$ & Roma 277; Álvarez Burgos tipo 566 & $19 \mathrm{~mm} ., 0,6 \mathrm{~g}$. & Idem \\
\hline DX0016/69 & \begin{tabular}{|l|} 
Blanca de rombo de \\
Enrique IV, ENRI(CVS)DEI \\
GRA REX castillo dentro de \\
gráfila, debajo venera. \\
XPS VINCIT XPX (REGNAT) \\
león coronado dentro de \\
gráfila losange.
\end{tabular} & $\begin{array}{l}\text { Álvarez Burgos tipo 827; } \\
\text { Paz tipo } 368\end{array}$ & $19 \mathrm{~mm} ., 1 \mathrm{~g}$. & Idem \\
\hline DX0016/71 & \begin{tabular}{|l|} 
Juan I de Portugal, IHNS \\
DEI GRA REX cruz patada \\
con rosetas en cuadrantes, \\
dentro de círculo; () GRA \\
REX, escudetes ligados con \\
rosetas en cuadrantes. \\
\end{tabular} & Ver abajo & $22 \mathrm{~mm} ., 2,1 \mathrm{~g}$. & Idem \\
\hline DX0016/72 & $\begin{array}{l}\text { Juan I Portugal ADIVTORIVM } \\
\text { NOSTRVM... EECIT CELLVM } \\
\text { ETE... Y coronada dentro de } \\
\text { gráfila circular, arriba punto, } \\
\text { a la izquierda signo y punto; } \\
\text {... PO...REX, cinco quinas en } \\
\text { cruz en similar gráfila. }\end{array}$ & Ver abajo & $28 \mathrm{~mm} ., 2,3 \mathrm{~g}$. & Idem \\
\hline DX0016/73 & $\begin{array}{l}\text { Dinero de Tours, (TV)RONVS } \\
\text { CIVI, cruz patada dentro de } \\
\text { círulo; SCS (MARTI)NVS, } \\
\text { castillo tornés. }\end{array}$ & & $\begin{array}{l}19 \text { mm., } 0,7 \mathrm{~g} . \\
\text { Años } 1001-1200\end{array}$ & Idem \\
\hline DX0016/74 & $\begin{array}{l}\text { Blanca de rombo de } \\
\text { Enrique IV, (ENRICV)S DEI } \\
\text { GRA REX, castillo dentro de } \\
\text { gráfila losange, debajo B; } \\
\text { (XPS VINCI)T XPS REGNAT, } \\
\text { león rampante y coronado } \\
\text { en idéntica gráfila. }\end{array}$ & $\begin{array}{l}\text { Álvarez Burgos tipo 827; } \\
\text { Paz tipo } 368\end{array}$ & $\begin{array}{l}20 \mathrm{~mm} . ; 1,2 \mathrm{~g} . \\
\text { Diversos sectores }\end{array}$ & Idem \\
\hline DX0016/75 & \begin{tabular}{|l|} 
Blanca de rombo de \\
Enrique IV, ENRICVS DEI \\
GRA REX, castillo en gráfila \\
losagne, debajo venera. XPS \\
VINCIT, en misma gráfila.
\end{tabular} & $\begin{array}{l}\text { Álvarez Burgos tipo 827; } \\
\text { Paz tipo } 368\end{array}$ & $19 \mathrm{~mm}, 0,8 \mathrm{~g}$ & Idem \\
\hline
\end{tabular}




\begin{tabular}{|c|c|c|c|c|}
\hline Inventario & Moneda & Principales catálogos & Metrología & Procedencia \\
\hline DX0016/76 & $\begin{array}{l}\text { Ceitil de Alfonso V...A... } \\
\text { tres torres sobre muralla } \\
\text { bañada por el mar........ } \\
\text { escudo con quinas dispues- } \\
\text { tas en forma de cruz, canto- } \\
\text { nada de castillos. }\end{array}$ & A. Gomes tipo 06.03, págs $125-129$ & $23 \mathrm{~mm} ., 1 \mathrm{~g}$. & Idem \\
\hline DX0016/78 & $\begin{array}{l}\text { Doblada y con total } \\
\text { desgaste, inclasificable. }\end{array}$ & & $23 \mathrm{~mm} ., 1,4 \mathrm{~g}$. & Idem \\
\hline DX0016/79 & $\begin{array}{l}\text { Juan I Portugal, ADIVIORVM } \\
\text { NOSTR(VM QVIF/ EECIT } \\
\text { CELLVM E TE... dentro de } \\
\text { gráfila circular, Y coronada } \\
\text { arriba, punto, a izquierda } \\
\text { signo y estrella; (IHN)S } \\
\text { DE(I GRA RE) POET (AL) } \\
\text { cinco quinas en gráfila } \\
\text { polilobulada. }\end{array}$ & $\begin{array}{l}\text { Dos son un real preto (A. Gomes } \\
\text { tipo } 01.01 \text { pág 109), el otro } \\
\text { asemeja un cuarto de real cruzado } \\
\text { (A. Gomes tipo } 09.01 \text { pág 109) }\end{array}$ & $26 \mathrm{~mm} ., 2,6 \mathrm{~g}$. & Idem \\
\hline DX0016/80 & $\begin{array}{l}\text { +IOHANES REX CASTEL, } \\
\text { castillo dentro de gráfila } \\
\text { lobular; + IOHANES REX } \\
\text { LEGIONI, león rampante a } \\
\text { izquierda dentro de } \\
\text { idéntica gráfila. }\end{array}$ & & $23 \mathrm{~mm} ., 1,4 \mathrm{~g}$. & Idem \\
\hline DX0016/81 & $\begin{array}{l}\text { Ceitil de Alfonso V Portugal, } \\
\text { (ALFO): REIS: PORTU(GAL), } \\
\text { A coronada dentro de } \\
\text { círculo, debajo P. AIVG... } \\
\text { dentro de círculo lobulado } \\
\text { cinco quinas en cruz. }\end{array}$ & A. Gomes tipo 06.03 , págs $125-129$ & $22 \mathrm{~mm} ., 1,6 \mathrm{~g}$. & Idem \\
\hline DX0016/82 & \begin{tabular}{|l} 
Blanca de rombo de \\
Enrique IV, (ENRICUSD)EI \\
G(RA REX) castillo dentro \\
de gráfila en losagne, \\
debajo venera. (XPS.....) \\
León rampante coronado \\
en misma gráfila.
\end{tabular} & $\begin{array}{l}\text { Álvarez Burgos tipo 827; } \\
\text { Paz tipo } 368\end{array}$ & $19 \mathrm{~mm} ., 0,7 \mathrm{~g}$. & Idem \\
\hline $\begin{array}{l}\text { DX0016 } \\
/ 124\end{array}$ & Dos monedas, una doblada & & $\begin{array}{l}\text { La grande vellón } \\
\text { bajomedieval. } \\
\text { Total desgaste. }\end{array}$ & Idem \\
\hline DX0105/1 & $\begin{array}{l}\text { Moderna, cortadillo de } \\
\text { Felipe II }\end{array}$ & & & $\begin{array}{l}\text { Rúa Hernán } \\
\text { Cortés, n 38-40 } \\
\text { Ourense. } \\
\end{array}$ \\
\hline DX0112/3 & $\begin{array}{l}3 \text { monedas? Sólo se } \\
\text { encuentran dos, ilegibles }\end{array}$ & & & $\begin{array}{l}\text { Rúa San Miguel, } \\
\text { 6, Ourense. }\end{array}$ \\
\hline
\end{tabular}




\begin{tabular}{|c|c|c|c|c|}
\hline Inventario & Moneda & Principales catálogos & Metrología & Procedencia \\
\hline DX0435/13 & 1 moneda & & & $\begin{array}{l}\text { Rúa Porta Nova } \\
\text { de Abaixo, } 5, \\
\text { Ribadavia } \\
\text { (San Domingos). }\end{array}$ \\
\hline DX1004/1 & $\begin{array}{l}\text { Dinero de Dinis I de } \\
\text { Portugal, anverso ilegible, } \\
\text { cruz cantonada con estrella } \\
\text { en primer y cuarto cuarte- } \\
\text { les, luna en restantes. } \\
\text { Reverso ilegible. Quizás ya } \\
\text { de Alfonso III. }\end{array}$ & A. Gomes tipo 01.01, págs. 76-77 & & $\begin{array}{l}\text { Edificio del } \\
\text { Museo de } \\
\text { Orense. }\end{array}$ \\
\hline DX1004/2 & $\begin{array}{l}\text { Ceitil de Juan III Portugal } \\
(+I O A N E S . R) P(A) \text { castillo } \\
\text { de tres torres y muralla } \\
\text { bañados por mar. } \\
\text { (+IO)AN(ES) borroso. } \\
\text { Ya moderna. }\end{array}$ & Ya moneda moderna. & $18 \mathrm{~mm}$. & Idem \\
\hline DX1004/6 & Pujesa de Alfonso X & Roma 209; Álvarez Burgos tipo 280 & $18 \mathrm{~mm}$. & Idem \\
\hline DX1004/8 & \begin{tabular}{|l|} 
Dinero Alfonso IX, \\
León a derecha y LE0
\end{tabular} & Roma 134; Álvarez Burgos tipo 120 & $19 \mathrm{~mm} ., 0,9 \mathrm{~g}$. & Idem \\
\hline DX1005/52 & $\begin{array}{l}\text { Alfonso X, dinero seis } \\
\text { líneas ALF/ ONSUS/REX } \\
\text { CAS/TELLEE/TLEIO/NIS. } \\
\text { Gráfila de puntos. Reverso } \\
\text { de castillos y leones cuarte- } \\
\text { lados, dentro de idéntica } \\
\text { gráfila. }\end{array}$ & Roma 199; Álvarez Burgos tipo 227 & & Idem \\
\hline DX1006/39 & $\begin{array}{l}\text { Moneda ilegible, } \\
\text { vellón fuerte? }\end{array}$ & & $19 \mathrm{~mm}$. & Idem \\
\hline DX1006/41 & \begin{tabular}{|l|} 
Dinero casi ilegible \\
(Roma 201 ó 215), legionis? \\
Leyendas desgastadas.
\end{tabular} & Roma 201; Álvarez Burgos tipo 248 & & Idem \\
\hline DX1006/42 & $\begin{array}{l}\text { Vellón de Portugal, quinas } \\
\text { en cruz, gran desgaste. }\end{array}$ & A. Gomes tipo 01.01, págs. $76-77$ & & Idem \\
\hline DX1006/43 & $\begin{array}{l}\text { Vellón castellano de gráfila } \\
\text { Losagne, gran desgaste, } \\
\text { módulo grande. }\end{array}$ & & & Idem \\
\hline DX1006/44 & Idem, desgaste. & & & Idem \\
\hline DX1006/45 & $\begin{array}{l}\text { Vellón de Portugal, fuerte } \\
\text { desgaste aunque se } \\
\text { distinguen quinas en cruz. }\end{array}$ & A. Gomes tipo 01.01, págs. $76-77$ & & Idem \\
\hline DX1006/47 & $\begin{array}{l}\text { Trozos de cruz similar a la } \\
\text { anterior, quinas? }\end{array}$ & A. Gomes tipo 01.01, págs. 76-77 & & Idem \\
\hline
\end{tabular}




\begin{tabular}{|c|c|c|c|c|}
\hline Inventario & Moneda & Principales catálogos & Metrología & Procedencia \\
\hline DX1176/1 & $\begin{array}{l}\text { Real de Enrique Il de } \\
\text { Castilla., ceca venera. }\end{array}$ & Roma 257; Álvarez Burgos 404 & & $\begin{array}{l}\text { Necrópolis } \\
\text { rupestre de San } \\
\text { Vítor, San } \\
\text { Lourenzo de } \\
\text { Barxacova, } \\
\text { Parada de Sil, } \\
\text { Terra de Caldelas, } \\
\text { Orense. }\end{array}$ \\
\hline DX1176/2 & Alfonso V de Portugal, Porto. & A. Gomes tipo 06.03, pág 125 & & Idem \\
\hline DX1176/3 & $\begin{array}{l}\text { Dinero Fernando I de } \\
\text { Portugal. }\end{array}$ & A. Gomes tipo 02.01, pág 82 & & Idem \\
\hline DX1176/4 & $\begin{array}{l}\text { Cornado Sancho IV, torre } \\
\text { central baja, con lo que no } \\
\text { es de Alfonso XI. }\end{array}$ & Roma 211; Álvarez Burgos tipo 294 & & Idem \\
\hline DX1040/25 & \begin{tabular}{|l|} 
Vellón de Portugal, se \\
dintinguen quinas, la \\
descripción no se corres- \\
ponde con la imagen
\end{tabular} & & $17 \mathrm{~mm} ., 0,86 \mathrm{~g}$. & $\begin{array}{l}\text { Capilla de Santa } \\
\text { Catarina, Reza } \\
\text { Vella, Santiago } \\
\text { das Caldas, } \\
\text { Orense. }\end{array}$ \\
\hline DX0062/16 & $\begin{array}{l}\text { Vellón de Portugal, como } \\
\text { el anterior fuerte desgaste, } \\
\text { aunque sin duda se dintin- } \\
\text { guen castillo y quinas. }\end{array}$ & & & $\begin{array}{l}\text { Igrexa de Santa } \\
\text { Mariña, Xinzo } \\
\text { de Limia, } \\
\text { Orense. }\end{array}$ \\
\hline $\begin{array}{l}\text { CE005233 } \\
/ 57\end{array}$ & Ceitil de Portugal & $\begin{array}{l}\text { El tipo se inicia con Alfonso V } \\
\text { (A. Gomes tipo 06.03, pág 125) }\end{array}$ & $16 \mathrm{~mm}$. & \begin{tabular}{|l} 
Aquae \\
Querquennae, \\
Porto Quintella, \\
Bande, Orense.
\end{tabular} \\
\hline $\begin{array}{l}\text { CE005225 } \\
/ 7\end{array}$ & $\begin{array}{l}\text { Portugal. Castillo de tres } \\
\text { torres, muralla sobre mar; } \\
\text { quinas }\end{array}$ & \begin{tabular}{|l|} 
El tipo se inicia con Alfonso V \\
(A. Gomes tipo 06.03, pág 125)
\end{tabular} & 17 mm., $1,5 \mathrm{~g}$. & $\begin{array}{l}\text { Castro Coto do } \\
\text { San Trocado, } \\
\text { San Amaro, } \\
\text { 0 Carballiño, } \\
\text { Orense. }\end{array}$ \\
\hline CE003625 & $\begin{array}{l}\text { Dinero de Alfonso VI, } \\
\text { a día de hoy ilocalizado. }\end{array}$ & & $21 \mathrm{~mm}$. & $\begin{array}{l}\text { Catedral de } \\
\text { Santiago de } \\
\text { Compostela. } \\
\text { Se cita aunque } \\
\text { no consta en } \\
\text { este fondo. } \\
\text { Suponemos que } \\
\text { es uno de los } \\
\text { hallados en } \\
\text { dicha catedral, } \\
\text { ya citados por } \\
\text { Suárez Otero. }\end{array}$ \\
\hline
\end{tabular}




\section{BiBLIOGRAFÍA}

Álvarez Burgos, Fernando, Catálogo de la moneda medieval castellano-leonesa. Siglos XI al $X V$, Madrid, Vico-Segarra, 1998.

Aulló Costilla, Manuel, “Cornados de Sancho IV”, Nvmisma, 16 (1955), págs. 65-85.

Cabral, Joào Manuel Peixoto y Metcalf, David Michael, A moeda sueva. Suevic Coinage, Porto, Sociedade Portuguesa de Numismática, 1997.

Cantilena, Renata, "Un obolo per Caronte?", Caronte, un obolo per l'ldilà. Pdp 50, III-VI (1995), págs. 165-177.

Casal García, Raquel, González Vila, Goretti, Roma Valdés, Antonio, "Monedas de Enrique II fabricadas entre 1369 y 1373: una posible emisión compostelana", Gaceta numismática, 174-175 (2009), págs. 21-34.

Cavada Nieto, Milagros, Galicia romana, circulación monetaria, tesis doctoral inédita, Santiago de Compostela, Universidad de Santiago de Compostela, 1973.

Cayón, Adolfo, Cayón, Clemente y Cayón, Juan, Las monedas españolas: del tremis al euro. Vol. 2: del 411 a nuestros días, Madrid, Cayón-Jano, 2005.

Ceci, Francesca, "La deposizione nella tomba. Continuità di un rito tra paganesimo e cristianesimo", Historia Antiqua, 13 (2005), págs. 407-416.

Crusafont i Sabater, Miquel, "Significado y valor del sólido gallecano (s.X-XI)", en Francisco Cebreiro Ares (ed.), Introducción a la Historia monetaria de Galicia, s. II a.C.-XVII d.C., A Coruña, Labirinto de Paixóns, 2012, págs. 105-116.

David, Pierre, Études historiques sur la Galice et le Portugal du VI au XII siècle, Coimbra, Instituto de Estudios Históricos, 1947.

Doménech Belda, Carolina, "Moneda y espacios de poder en el mundo visigodo. Los trémises de El Tolmo de Minateda (Hellín, Albacete), Arqueología y territorio medieval, 21 (2014), págs. 9-38.

Duby, Georges, Economía rural y vida campesina en el Occidente medieval, Barcelona, Península, 1973.

Francisco Olmos, José María de; Novoa Portela, Feliciano, Catálogo de numismática do Museo das Peregrinacións e de Santiago, Santiago de Compostela, Xunta de Galicia, 2009.

Gomes, Alberto, Moedas portuguesas: e do território português antes da fundaçao da nacionalidade. Catálogo das moedas cunhadas para o continente e ilhas adjacentes e para os territórios do ultramar e grao-mestres portugueses da Ordem de Malta, Lisboa, Associaçao Numismática de Portugal, 2001.

Graells i Fabregat, Raimon, "Sobre el primer culto a Caronte en noreste de la península Ibérica, datos para su discusión”, Gallaecia, 32 (2013), págs. 21-45.

Marques, Mário Gomes, A moeda peninsular na idade das trevas, Sintra, Instituto de Sintra, 1998.

Mozo Monroy, Manuel y García Montes, Francisco Javier, “Primeras labras de vellón acuñadas en Toledo (ss. XI-XII). Propuesta de interpretación iconográfica", Parva Urbs, 0 (2009), págs. 16-18.

Mozo Monroy, Manuel y García Montes, Francisco Javier, “Aporte histórico y documental sobre el dinero de busto godo de Alfonso VI, rey de León y Castilla", Gaceta Numismática, 180 (2011), págs. 67-82. 
Núñez Meneses, Pablo, “Economía natural o monetaria en la Galicia de los siglos VIII al XI?”, OMNI, 6 (2013), págs. 146-155.

Núñez Meneses, Pablo, "Hallazgos de moneda visigoda en Galicia", ANVAR.es (noviembre de 2014) [en línea], disponible en < http:/www.anvar.es/2014/11/hallazgos-de-moneda-visigoda-en-galicia/> [Consulta: 15/12/2015].

Núñez Meneses, Pablo, "Hallazgo de Ordes del Museo Provincial de Lugo", en XV Congreso Nacional de Numismática, Madrid, Museo Arqueológico Nacional, 2016.

Núñez Meneses, Pablo, "Moneda y mundo rural en la documentación samonense medieval", en Actas del Lugo Numismático 2016, a publicar en ANVAR.es (julio 2016).

Orol Pernas, Antonio, Acuñaciones de Alfonso IX, Madrid, Vico, 1982.

Paz Bernardo, Jaime, Moedas galegas: moedas, medallas, billetes: especializado do século IX a.C. ó século XXI d.C., Barcelona, Numismática J. Paz, 2002.

Pliego Vázquez, Ruth, La moneda visigoda, vols. I y II, Sevilla, Universidad de Sevilla, 2009.

Pliego Vázquez, Ruth, "Gallaecia en tiempos del reino visigodo de Toledo", en Francisco Cebreiro Ares (ed.), Introducción a la Historia monetaria de Galicia, s. II a.C.-XVII d.C., A Coruña, Labirinto de Paixóns, 2012, págs. 65-104.

Ríos Rodríguez, María Luz, As orixes do foro na Galicia medieval, Santiago de Compostela, USC, 1993.

Roma Valdés, Antonio, Moneda y sistemas monetarios en Castilla y en León durante la Edad Media (1087-1366), Barcelona; Madrid, ANE; MCM, 2000.

Roma Valdés, Antonio, Emisiones monetarias leonesas y castellanas de la Edad Media. Organización, economía, tipos y fuentes, [s.1.], Morabetino, 2010.

Rodríguez García, Purificación, Fariña Busto, Francisco, “Tesorillo monetario de Monte Rego", Boletín Auriense, XLIV (2015).

Rueda Sabater, Mercedes, Primeras acuñaciones de Castilla y León, Salamanca, Junta de Castilla y León y Asociación Española de Arquología medieval, 1991.

Rueda Sabater, Mercedes y Sáez Sáiz, Inmaculada, "Hallazgos medievales de moneda castellana y leonesa”, Numisma, 230 (1992), págs 205-260.

Sánchez Rincón, Raúl, Roma Valdés, Antonio, "La otra cara de la moneda. Uso y reutilización de la moneda en la Edad Media del Noroeste Peninsular (II)", Numisma, 258 (2015), págs. 143-172.

Suárez Otero, José, "Conjunto de monedas medievales aparecidas en las excavaciones de la Catedral de Santiago", en Serafín Moralejo y Fernando López Alsina (eds.), Santiago, camino de Europa. Culto y cultura en la peregrinación a Compostela, Madrid, Caja de Madrid, 1993, págs. 279-283.

Suárez Otero, José, “Aproximación á colección arqueolóxica da Universidade de Santiago", en Gallaecia Fulget: (1495-1995): Cinco séculos de historia universitaria, Santiago de Compostela, 1995, págs. 476-479.

Suárez Otero, José, “Arqueología y Peregrinación. La moneda en la Peregrinación marítima a Santiago", en Actas del II Congreso Internacional de Estudios Jacobeos: rutas atlánticas de peregrinación a Santiago de Compostela: Ferrol, septiembre de 1996, Santiago de Compostela, 1998, págs. 197-218. 
Suárez Otero, José, "Moneda, peregrinación y comercio. Una nueva perspectiva del Camino de Santiago en la Edad Media", en Serafín Moralejo y Fernando López Alsina (eds.), VIII Memorial Filgueira Valverde. Reflejos da peregrinación e do culto a Santiago, Pontevedra, Universidad de Vigo, 2009, págs. 81-114.

Suárez Otero, José, "La moneda en el edículo apostólico de la catedral de Santiago", en Serafín Moralejo y Fernando López Alsina (eds.), VIII Memorial Filgueira Valverde. Reflejos da peregrinación e do culto a Santiago, Pontevedra, Universidad de Vigo, 2009, págs. 275-279.

Vaz, J. Ferraro y Salgado, Javier, Livro de moedas de Portugal, Braga, Livraria Cruz, 1969.

Vázquez Seijas, Manuel, "De re numismatica", Boletín de la Comisión Provincial de Monumentos Históricos y Artísticos de Lugo, Tomo II, n. 17-18 (1940), págs. 186-188. 